Revista lus et Praxis, Año 24, № 1, 2018, pp. 553 - 592

ISSN 0717 - 2877

Universidad de Talca - Facultad de Ciencias Jurídicas y Sociales

La imputabilidad o capacidad como elemento de la responsabilidad civil extracontractual. Un debate pendiente en la doctrina chilena

Lilian C. San Martín Neira

Trabajo recibido el 9 de agosto de 2016 y aprobado el 28 de marzo de 2017

\title{
La imputabilidad o capacidad como elemento de la responsabilidad civil extracontractual. Un debate pendiente en la doctrina chilena
}

TORTIOUS CAPACITY AS AN ELEMENT OF THE TORT LAW. AN OUTSTANDING DEBATE IN THE CHILEAN DOCTRINE

Lilian C. San Martín Neira*

\begin{abstract}
RESUMEN
Este trabajo se enmarca en el estudio de la culpa de la víctima, específicamente en el análisis de la posibilidad de atribuir una culpa concurrente a las víctimas incapaces de cometer delito o cuasidelito civil. Según se demuestra, la posición que se adopte con relación a este punto exige tener resuelto un aspecto previo: el rol de la imputabilidad, o capacidad para cometer delito, en el juicio de responsabilidad civil. Aspecto que ha sido arduamente debatido en algunos países y que repercute en otros aspectos de la responsabilidad civil, como es la legitimidad pasiva en hipótesis de responsabilidad objetiva. En Chile, esta problemática no ha sido directamente abordada, de ahí que el principal objetivo de este trabajo sea plantear la discusión a nivel nacional, evidenciando su importancia. Para ello se ofrece un estudio histórico-comparado sobre el rol que ha tenido la imputabilidad en la estructura de la responsabilidad civil.
\end{abstract}

\section{ABSTRACT}

This paper is part of a study regarding the victim's contributory negligence, specifically in analyzing the possibility of attributing contributory negligence to the victims without tortious capacity. It demonstrates that the position taken in relation to this point requires a previous aspect to be resolved: the role of tortious capacity in the judgment of civil liability, an aspect that has been arduously discussed in some countries and which has an impact on other aspects of civil liability, such as passive legitimacy in the hypothesis of objective liability. In Chile, this problem has not been directly addressed, hence the main objective of this work is to raise the discussion at the national level, showing its importance. With that purpose, it offers a historical-comparative study about the role of tortious capacity in the structure of the non-contractual liability.

\footnotetext{
* Facultad de Derecho Universidad Alberto Hurtado. Cienfuegos 41, Santiago de Chile, Isanmar@ uahurtado.cl. Este trabajo forma parte del proyecto Fondecyt Iniciación, 11140246, del cual la autora es investigadora responsable.
} 


\section{Introducción}

Una cuestión muy debatida en torno a la culpa concurrente de la víctima es la pertinencia de esta institución respecto de las víctimas incapaces de cometer delito o cuasidelito, esto es, aquellas que son inimputables por carecer de juicio y discernimiento ${ }^{1}$. En concreto, surge la pregunta ipuede aplicarse la reducción por culpa concurrente a un niño de seis años que electrocuta, luego de ingresar sin permiso a una central eléctrica? $?^{2}$ Antes que todo, la respuesta a esta pregunta pasa por determinar, si la autorresponsabilidad de la víctima exige los mismos requisitos de la responsabilidad del agente. En la mayoría de los ordenamientos extranjeros, de tradición romanista y de Common Law, sí se exigen tales requisitos, dando lugar a lo que se ha denominado la doctrina del espejo $^{3}$. La misma idea se ha seguido tradicionalmente en Chile, pues la doctrina ha afirmado que respecto de la víctima deben concurrir todos los presupuestos de la responsabilidad civil, especialmente la culpa ${ }^{4}$, ya que el Código Civil (artículo 2330) alude a la imprudencia de la víctima. Sin embargo, en las dos últimas décadas algunos autores han propuesto que es necesario diferenciar entre agente y víctima, afirmando que respecto de la víctima no sería necesario el juicio de imputabilidad, impuesto expresamente por el artículo 2319 CC. $\mathrm{Si}$ bien tales autores coinciden en el resultado, las justificaciones no siempre son concordantes. Así, Barros afirma que "resulta discutible que la culpa de la víctima requiera del requisito de la capacidad, porque es distinta la atribución de responsabilidad a un incapaz de la pretensión de éste de ser indemnizado; en la medida que la conducta del incapaz es objetivamente descuidada (como el niño que atraviesa sorpresivamente una calle), no hay razón para no considerarla al momento de medir la intervención causal que ha tenido el ilícito del

\footnotetext{
1 Para efectos de este trabajo, imputabilidad es equivalente a capacidad delictual o cuasidelictual, en consecuencia, salvo que se haga expresa advertencia, se las utilizará como sinónimos. Estamos conscientes de la crítica que efectúa un sector de la doctrina a este modo de proceder ( $v$. gr. ABELIUK (2014), p. 284), pero lo cierto es que la nomenclatura no empece los objetivos de este trabajo y estimamos que la idea de imputabilidad se condice mucho mejor con la idea de discernimiento, que es finalmente lo que se exige.

2 Esta fue la respuesta que debió contestar la Corte Suprema en el caso Castilla Treviño Gillermo con S. Austral Electricidad, en la cual resuelve que la falta de capacidad delictual de la víctima impide que a su respecto se aplique el artículo 2330, lo mismo que respecto de sus hermanos menores. En todo caso, esto no impide que se aplique la reducción a los padres del menor, que con su conducta descuidada permitieron que el accidente ocurriera. Castilla Treviño Guillermo con Sociedad Austral electricidad (2006).
}

3 Martín-Casals (2003), pp. 2471-2490; Martín-Casals (2007), pp. 1-317.

4 Alessandri (2004), pp. 412 y 448; Domínguez (1996), pp. 29-54, pp. 36 ss.; Díez (1997), pp. 225 ss.; TAPIA (2006), pp. 258-259. 
demandado $(. . .)^{\prime \prime}$. Luego, el mismo autor agrega que "el niño que cruza la calle en un lugar imprevisible tiene una intervención de tal manera significativa en la producción del daño, que no resulta justo que sea imputado exclusivamente al conductor que conducía a exceso de velocidad. La culpa de la víctima no es un juicio de reproche sobre su conducta, sino una especie de inoponibilidad total o parcial en el juicio de atribución del daño, que el tercero hace valer con fundamento en que parte del daño no puede ser imputado (al menos totalmente) a su propia negligencia" ${ }^{\prime \prime}$. En la misma línea, Corral asegura que para aplicar el artículo 2330 no es necesario el juicio de imputabilidad, porque "se trata más bien de una conducta de la víctima por la que se interviene el suceder causal que da como resultado el daño. Siendo así, la exposición imprudente puede ser debida a una persona inimputable ${ }^{\prime \prime}$. Una opinión matizada sostienen Pizarro y Bahamondes, para quienes el artículo 2330 no puede aplicarse a los incapaces de cometer delito o cuasidelito, porque no incurren en culpa, pero llegan a la misma conclusión a través de la causalidad, afirmando que "(...) si el incapaz ha causado parte de su daño, el victimario sólo deberá responder de aquella parte que le resulta pertinente conforme a los parámetros de la causalidad. Si bien el artículo 2330 CC. es impertinente en la especie, no lo es la regla de causalidad. Entenderlo de otra forma implicaría un enriquecimiento injustificado para la víctima quien habiéndose causado en parte del perjuicio podría recolectar el total de la indemnización que la rebaja proceda, conforme al artículo 2330 CC." ${ }^{\prime \prime}$.

A simple vista, el problema se reduciría a una tensión entre dos ideas: (i) considerar que la culpa concurrente constituye una cuestión de causalidad, en cuyo caso sí resulta pertinente la reducción; o (ii) considerar que la culpa concurrente de la víctima es una cuestión de culpa, en cuyo caso ella no resulta pertinente ${ }^{9}$. Sin embargo, un análisis más detenido muestra que el debate es anterior a esa disyuntiva y pasa por establecer el rol que juega la imputabilidad al interior del juicio de responsabilidad: ¿ es un requisito autónomo o un componente de la culpa? En efecto, según la doctrina de la llamada culpa objetiva o social, la imputabilidad no se relaciona con la culpa, sino que, para el caso que el ordenamiento jurídico la exija (hay algunos que no lo hacen), se trataría

\footnotetext{
5 Barros (2006), p. 429.

6 Barros (2006), p. 434.

Corral (2013), p. 197.

8 Bahamondes y Pizarro (2012), p. 48.

9 Esta forma de enfrentar el argumento ha sido desarrollada con claridad en Aedo (2013), pp. 505 ss., pero se desprende también de todos los trabajos que aluden al argumento.
} 
de un supuesto de la responsabilidad civil en general y operaría como una eximente de responsabilidad. Bajo esta perspectiva, el problema que nos ocupa no consistiría en determinar si la culpa concurrente de la víctima constituye una cuestión de culpa o causalidad, sino en establecer el rol que la imputabilidad cumple en la estructura de la responsabilidad civil. Esta idea se aprecia claramente al analizar el pensamiento de los hermanos Mazeaud, quienes, como se verá, admiten que la culpa concurrente constituye una cuestión de culpa, pero, dado que para ellos la imputabilidad no es un elemento de la culpa, admiten también la reducción del resarcimiento por culpa concurrente de las víctimas inimputables.

En síntesis, el análisis respecto a si la culpa de la víctima es una cuestión de culpa o de causalidad, supone definir el rol que juega la imputabilidad en la responsabilidad civil, específicamente, si ella integra el concepto de culpa o es un elemento independiente, cuestión que trasciende con creces el problema de la culpa de las víctimas incapaces. En efecto, la conclusión a que se llegue redundará directamente en otro aspecto fundamental de la responsabilidad civil: los legitimados pasivos en las hipótesis de responsabilidad objetiva. En la medida que se concluya que la incapacidad es una cuestión atingente a la culpa, los incapaces podrán responder en sede responsabilidad objetiva. Si, por el contrario, se concluye que la imputabilidad es un elemento independiente, los incapaces no responden tampoco en este género de responsabilidad.

A diferencia de lo que ha ocurrido en otros países, como Francia e Italia, en Chile, este debate no se ha producido, solo hay referencias aisladas en doctrina y jurisprudencia. De ahí que el principal objetivo de este trabajo sea exponer el rol que históricamente ha jugado la imputabilidad en la estructura de la responsabilidad civil y las mutaciones que este rol ha tenido en algunos ordenamientos, con el fin de invitar a la doctrina chilena a reflexionar sobre si en nuestro país ese rol sigue siendo el mismo o bien ha cambiado.

\section{La culpa subjetiva o moral y la culpa objetiva o social como alternativas conceptuales en derecho comparado}

\section{La culpa subjetiva: la imputabilidad como elemento integrante de la noción romana de culpa}

La culpa ha sido un concepto controvertido en la historia del Derecho, múltiples autores han intentado señalar en qué consiste y rastrear sus orígenes, sin que exista consenso al respecto ${ }^{10}$, pero lo cierto es que los juristas romanos

10 AEDO (2014 b), pp. 27-57. Un análisis más extenso de estos conceptos puede verse en la tesis doctoral del mismo autor, a quien agradezco la gentileza de haberme permitido consultarla. AEDo (2010). 
dejaron para la posteridad el concepto de culpa ${ }^{11}$ y ha sido recogido en los ordenamientos jurídicos modernos, especialmente en aquellos de tradición romanista. Ahora bien, como ha demostrado Schipani ${ }^{12}$, en su sentido etimológico, el término culpa encierra una calificación de la conducta, un juicio de valor, pues ella "conserva una unidad con la voz culpare, que significa en unos casos 'inculpar', en otros 'reprochar' y pone en evidencia un dinamismo social, intersubjetivo, dialógico y crítico en relación al sujeto agente" ${ }^{\prime 13}$. De ahí que en la lengua latina hasta fines de la República -época en que se testimonia el comienzo de su utilización técnica por los jurisconsultos- la voz culpa se relacionaba con la presentación de un hecho que constituía un malum, del cual una persona debía ser reconocida como autora. Además, era necesario que tal persona pudiera comportarse de manera distinta, sin estar impedida por factores externos o internos, que obstaculizaran su actuación ${ }^{14}$. Por último, la culpa no se refería solo a comportamientos intencionales, sino también a la falta de control del propio comportamiento en relación a un modelo que el sujeto debía seguir ${ }^{15}$. En resumen, además de la previsibilidad del daño ${ }^{16}$, en Derecho romano la culpa supone dos elementos: (i) el comportamiento desviado, en atención a un modelo objetivo de conducta, que llegó luego a identificarse con el buen padre de familia' ${ }^{17}$; y (ii) la posibilidad de actuar de modo diferente. La imputabilidad se relaciona con este segundo elemento; por lo tanto, es necesario detenerse un momento en él.

Para los juristas romanos, la culpa se relaciona con la decisión voluntaria de actuar, de ahí que para juzgar si el sujeto incurre en ella no se considere solo la conducta sostenida, sino las circunstancias antecedentes a la decisión de actuar

\footnotetext{
11 Según explica Talamanca, en la compilación Justinianea y en las fuentes jurídicas que nos han llegado fuera de ella, el término culpa asume un significado variable que se concreta, sustancialmente, en tres diversas acepciones: ilícito, imputabilidad y negligencia en sentido genérico. [TALAMANCA (1960), p. 518]. Así se explica que no resulte fácil saber qué entendían exactamente los juristas romanos por culpa.

12 Sobre el carácter irrefutable de la tesis de este autor en torno a la concepción originaria del vocablo culpa, afirma Cannata: "La compiutezza della documentazione non lascia dubbi sull'esattezza delle conclusioni raggiunte dallo S.". CANNATA (1971), p. 66.

13 SCHIPANI (2009), p. 59; para mayor profundización, véase el análisis en torno al origen y significado de la palabra 'culpa' en: SCHIPANI (1969), pp. 91 ss.

14 Para el análisis de estos factores véase SCHIPANI (1969), pp. 109 ss.

15 SCHIPANI (1995), p. 28; Véase también SChIPANI (1969), pp. 130-131; SCHIPANI (2009), p. 7; CannatA (1971), pp. 68 y 78-79; Castresana (2001), p. 70; Cardill (1995), pp. 223 ss.; Cardill (1996), p. 80.

16 En palabras de Valditara, "nonostante I'assenza di una affermazione esplicita resulta in ogni caso delle fonti come la commisurazione del comportamento alla stregua del criterio della diligenza del bonus pater implicasse anche la possibilità astratta di prevedere un certo esito dannoso". VALDITARA (2005), p. 69.

17 Rosso Elorriaga (2002), pp. 3 ss.
} 
y las medidas adoptadas para evitar que la propia actuación acarree daño. "Así, por ejemplo, el caso de quien llevando una carga pase por un lugar resbaloso y se caiga sobre un esclavo, aplastándolo (D.9,2,7,2): aquí la negligencia consistió en el hecho de haber elegido imprudentemente un camino peligroso en relación a la actividad que se debía llevar a cabo; asimismo, en la hipótesis de aquel que, podando un árbol, no haya tomado las precauciones para evitar que las ramas cayeran sobre los transeúntes o que, no pudiendo evitar de otra manera el peligro, no haya advertido a los extraños (D.9,2,31): aquí, la negligencia se encuentra en el hecho de no haber adoptado las medidas preventivas idóneas para impedir que se verificase el hecho dañino"18. En el mismo sentido, afirma Gayo (D.9.2.8.1) que incurre en culpa el mulero que "(...) por su poca fuerza no hubiere podido contener el ímpetu de las mulas. Y no parece injusto, si la escasez de fuerzas se cuenta para la culpa, porque nadie debe pretender hacer aquello en lo que o sabe, o debe saber, que su insuficiencia de fuerzas ha de ser peligrosa para otro $(\ldots)^{\prime \prime 19}$. Como explica Honoré, para Gayo, la culpa del mulero no radica en la acción misma de subir la cuesta capitolina, sino en el hecho de haber emprendido una actividad para la cual él sabía, o debía saber, que no estaba capacitado ${ }^{20}$. De esta manera, la posibilidad de actuar de modo diferente llevaba implícita la capacidad del sujeto para comprender el curso de sus acciones y la posibilidad de actuar conforme a esta comprensión, de ahí que excluyan la culpa todas aquellas circunstancias extrínsecas o intrínsecas que impidan al sujeto comportarse diversamente, tales como, estado de necesidad, caso fortuito, error excusable, enfermedad mental o bien inmadurez de juicio ${ }^{21}$. En particular, las fuentes romanas niegan la responsabilidad de los dementes y de los menores carentes de discernimiento, por no ser capaces de incurrir en iniuria ${ }^{22}$. En este sentido, puede verse D.9.2.5.2, en que Ulpiano afirma: "Y por esto preguntamos, si un furioso hubiere causado el daño, ¿habrá la acción de la ley Aquilia? Y Pegaso dijo que no; porque ¿qué culpa habría

\footnotetext{
18 Valditara (2005), p. 68.

19 García Del Corral (2004), tomo I, pp. 573-574.

20 HONORÉ (1999), p. 21; en el mismo sentido puede verse la extensa exégesis del pasaje realizada en SCHIPANI (1969), pp. 246 ss; Categóricamente en este sentido afirma Valditara que "nell'ambito di un contesto sifatto pure la infermitas e cioè la inidoneità fisica, o la imperitia, la incapacità tecnica, potranno dar luogo a culpa anche qualora il soggetto agente non potesse osservare comunque, in quella particolare circostanza, un comportamento diverso da quello tenuto; la assenza di diligenza in questo caso sarà ravvisabile nel fatto di non aver capito che la propria inhabilità poteva essere pericolosa per altri e nell'aver così egualmente intrapreso una certa attività". VALDITARA (2005), p. 69.

21 Schipani (1969), pp. 109 ss.; Valditara (2005), p. 39.

22 Para una explicación de la relación entre iniuria y culpa, en el sentido que damnum iniuria datum implicaría damnum culpa (o dolumn) datum, véase Zimmermann (1996), pp. 1004 ss.; Cursi (1992), pp. 86 ss.; GuZMán (2013), pp. 290-291.
} 
en él, no estando en su juicio? Y esto es muy verdadero; cesará, pues, la acción de ley Aquilia, así como no es aplicable la ley Aquilia si un cuadrúpedo hubieres causado el daño, o si hubiere caído una teja. Pero también si un infante hubiere causado daño, deberá decirse lo mismo. Pero si lo hubiere hecho un impúbero, dice Labeón, que puesto que se obliga por el hurto, quede el obligado también por la ley Aquilia; y opino que esto es verdad, si ya fuera capaz de injuria"23. En resumen, para los juristas romanos los dementes y los menores de siete años eran totalmente incapaces de culpa, mientras que los demás impúberes eran responsables solo en la medida en que hubieran adquirido el discernimiento, quedando entregado a la prudencia del juez determinar esta circunstancia ${ }^{24}$. Esta circunstancia se debía a que tales personas carecen de la posibilidad de adaptar su comportamiento y actuar de modo diferente.

Tal idea influenció el pensamiento de los autores del Derecho intermedio, especialmente a aquellos que influenciaron el Derecho castellano y francés, quienes Ilegaron a la convicción de que los carentes de discernimiento simplemente no podían incurrir en culpa y, por tanto, no podían ser acusados de delito o cuasidelito ${ }^{25}$. Para estos autores, "la imputación del daño exige una conducta libre y la suficiente capacidad del agente para prever las consecuencias lesivas de su comportamiento y, asimismo, mientras este se produce, reconocer en el la iniuria" ${ }^{26}$. A su vez, tal concepción puede verse en varias disposiciones de

23 García Del Corral (2004), tomo I, p. 572; expresamente en el sentido que la expresión capaz de injuria debe ser entendida en el sentido de capaz de culpa, CANNATA (1996), p. 26. En un sentido similar, aunque con mayores matices, CURSI (2002), pp. 92 ss.

24 Esta idea se encuentra magistralmente resumida por Jhering, quien, luego de haber afirmado el principio que no hay responsabilidad sin culpa, afirma: El que no sabe lo que hace, de nada responde. El enajenado mental, al que tantos Derechos Ilaman a indemnizar perjuicios, queda libre conforme al Derecho romano; su obrar, como el del animal, no está sometido a las leyes del mundo moral, sino a las del mundo material; es un suceso de la naturaleza externa semejante a la caída de una piedra. Sin embargo, así como el dueño del animal responde cuando le afecta alguna culpa, así también responden, en los mismos supuestos, las personas que tenían que cuidar del enajenado. Lo mismo puede decirse de los niños, no sólo los infantes en sentido técnico (hasta el término del séptimo año), sino también aquellos que han cumplido ya esta edad (infantia majores), pero en los que falta todavía la comprensión del carácter antijurídico de sus acciones. Sólo cuando aparece esta comprensión puede hacerse responder al hombre por sus acciones. Sin embargo, esta no se presenta de una vez, sino gradualmente, y no en el mismo instante para todos los individuos, sino en unos antes y en otros después; la imputabilidad, es síntesis, se da en estadio crítico. Teniendo esto en consideración, los juristas romanos no vinculan la responsabilidad de los infantia majores a un momento abstracto y fijo, sino que confían este problema a la apreciación individual del juez". VON JHERING (2013), p. 108.

25 Así lo sostiene expresamente Donellus, citado en WINIGER (2002), p. 81. Véase también PothiER (2007), p. 69.

26 Castresana (2001), p. 84. En el mismo sentido, Zimmermann (1996), p. 1033-1034 y 1044. 
las Siete Partidas ${ }^{27}$, especialmente P. $7^{\text {a }}$, tít. 1, L. 9; P. $7^{\text {a }}$, tít. 14, L. 17; P. $7^{\text {a }}$, tít. 15, L. 3.

\section{La preocupación por las víctimas y el surgimiento de la noción de culpa objetiva o social}

Como es sabido, la exigencia de culpa para traspasar el costo del accidente desde la víctima a un tercero implica que no todos los daños serán indemnizados, incluso si en ellos ha intervenido una acción humana independiente de la víctima. En la historia del Derecho, esta circunstancia ha motivado variadas críticas, que han llevado incluso a proponer la abolición de la culpa como requisito de la indemnización de perjuicios, con diferentes resultados ${ }^{28}$.

Un primer intento en tal sentido fue llevado a cabo por el iusnaturalismo germánico, que propuso visualizar la acción indemnizatoria no desde la óptica del delito, sino simplemente desde la óptica del daño causado, el cual debía ser reparado. "Su fundamento no es, por tanto, el hecho ilícito -la culpa- del agente, sino más bien la posición jurídica violada. No por casualidad esta acción de daños no tendría ningún carácter penal, sino que sería exclusivamente resarcitoria desde todo punto de vista. De aquí se siguen ulteriores consecuencias: si es necesario reestablecer en cualquier caso la posición jurídica violada, deberán responder también los locos o los infantes, serán llamadas a indemnizar los daños incluso personas cuyo hecho no puede serles imputado. En consecuencia, la responsabilidad tiende a objetivarse: la responsabilidad puede y debe prescindir de la culpa" ${ }^{29}$. La doctrina vigente está conteste en que esta construcción, con la consecuencia de imponer responsabilidad a los infantes y a los furiosos, se encuentra plasmada por primera vez en la obra de Christian Thomasius, específicamente en su obra Larva Legis Aquiliae ${ }^{30}$. En efecto, en esta obra este autor afirma que la única razón por la cual la acción de la Lex Aquilia no era procedente en contra de furiosos o infantes radicaba en que esta tenía un componente delictual, pero si los juristas se hubiesen centrado solo en el daño, habrían llegado a una decisión diferente ${ }^{31}$. Idea que

\footnotetext{
27 Cabe señalar que en las partidas se contiene una división de edades distintas a las del Derecho romano, pues se agregó la categoría de menores próximos a la pubertad, a partir de los diez años y medio, edad a partir de la cual el menor podía ser condenado por los delitos que cometiese, pero en lo demás se mantienen las reglas romanas.

28 Una panorámica de estas vicisitudes puede verse en López (2006), pp. 641-673.

29 Valditara (2005), p. 97.

30 Rotondi (1922), pp. 536 ss.; Zimmermann (1996), p. 1033; Castresana (2001), p. 87; Cursi (2002), pp. 54 ss.

31 "En Thomasius la acción de reparación del daño se hace derivar de la común tranquillitas, de la igualdad de género humano: ya no tiene sentido conservar el carácter penal de una acción general
} 
repite más adelante señalando que la acción de la ley Aquilia no mira a la persona del ofensor, sino a la cosa o propiedad por la cual la reparación es debida $^{32}$. De ahí que, para este autor, incluso cuando el daño se ha producido casu, nace la responsabilidad de quien colaboró a colocar al sujeto en situación de damnum ${ }^{33}$.

En síntesis, la justificación para eliminar la culpa como fundamento de la responsabilidad civil, era la naturaleza puramente resarcitoria y no penal de la acción aquiliana ${ }^{34}$. Tal idea permeó con fuerza la doctrina germánica previa a la codificación y, aunque la tradición romanista terminó por imponerse, pues los códigos consagraron la culpa como criterio central de atribución de responsabilidad ${ }^{35}$, lo cierto es que también la doctrina de Thomasius encontró una cierta acogida, que se revela especialmente en lo que respecta a los inimputables. En efecto, los códigos civiles de origen germánico, junto con afirmar la irresponsabilidad civil de los carentes de discernimiento, establecieron reglas que imponen a estas personas la obligación de pagar una indemnización ad aequitatem, bajo ciertos supuestos ${ }^{36}$.

Diferente fue la situación en la tradición francesa, pues los autores que influenciaron directamente la redacción del Code Civil, especialmente Domat, no pusieron en duda el hecho de que el fundamento de la responsabilidad

de resarcimiento de daños, cuya fuente ante los Tribunales de Justicia germánicos, no presenta una naturaleza sustancialmente penal, y de ahí que sea transmisible pasivamente, que no admita in fitiatione litiscrescencia, y, finalmente, que no tenga aplicación la repetitio temporis ni la solidaridad cumulativa". CASTRESANA (2001), p. 87.

32 En la preparación de este trabajo se ha tenido a la vista la versión en doble texto (latín e inglés) editada por Margaret Hewett. En especial, véase Thomasius (2000), pp. 20 ss. y 46 ss.

33 Castresana (2001), p. 84.

34 La naturaleza penal de la acción aquiliana había decaído a causa de otra discusión práctica importante, esto es, su transmisibilidad pasiva. Sobre esta cuestión, siguiendo el ejemplo del Derecho Canónico, se pronunciaron positivamente algunos juristas del ius commune y se consolidó en la escuela del Derecho natural, cuyos exponentes llegaron a la conclusión que, a causa de su carácter resarcitorio y no penal, la acción aquiliana es transmisible pasivamente y no litiscrescente, además, su aestimatio debe corresponder exactamente al daño actual. Estas serán las bases de la codificación, tanto francesa como germánica. Rotondi (1922), pp. 520 ss. y 536 ss.; SAvigny (2005), p. 786 ss.; DízZPicazo (2011), pp. 77 ss.

35 Una breve reconstrucción moderna de esta idea puede verse en ALPA (1990), pp. 133-155; ZIMMERMANN (1996), pp. 1032 ss.; Schiemman (2013), pp. 823-830, 840 y 842-853.

36 ABGB, artículo 1310 y BGB parágrafo 829. Tanto por influencia directa como indirecta, desde los códigos germánicos esta idea pasaría a algunos códigos modernos dictados en sustitución de los códigos decimonónicos de inspiración francesa. V. gr. CC. italiano, art. 2047; CC. portugués, art. 489; CC. peruano art. 1977; CC. brasileño, art. 928. Para una aproximación doctrinaria a estas disposiciones véase: Momigliano (1937), pp. 235 ss.; Leon (2005), 45 pp.; ProençA (2007), pp. 529 ss.; Simao (2008), 264 pp.; YÁÑEZ (2011), pp. 1301 ss. 
civil estaba en la culpa (faute $)^{37}$. Tampoco se puso en duda el hecho de que los carentes de discernimiento no eran capaces de culpa o dolo, dándolo como un supuesto "obvio" de la culpa y, por ende, del delito o cuasidelito ${ }^{38}$. Quizá por esta misma "obviedad", a diferencia de los germánicos, los autores del Código Civil no se preocuparon por dar reglas sobre la capacidad extracontractual, es así como la versión original del Código Civil francés no incluyó ninguna regla relativa a la capacidad para responder extracontractualmente. Para los primeros comentadores del Code Civil, tal silencio normativo no revistió inconveniente, pues, asumieron que la culpa exigía una actuación libre y, por tanto, uso de razón. Expresamente en este sentido, siguiendo la opinión de Pothier ${ }^{39}$, Delvincourt afirma que la culpa "supone una voluntad en aquel que ha cometido el hecho. Por lo tanto, aquellos a quienes se considera sin voluntad, no quedan sometidos a esta suerte de obligación; tales son los locos, los furiosos, los imbéciles. En cuanto a los menores, queda al juez decidir si cometió el hecho con discernimiento $(\ldots)^{\prime 40}$. Similarmente, Marcadé, sostiene que "el hecho, además de ser ilícito, debe ser imputable, esto es, verdaderamente voluntario y provenir de una libre determinación. En consecuencia, el niño de corta edad o el loco no pueden ser autores de un delito o cuasi delito"41. A la misma conclusión llegan otros autores del mismo periodo, quienes, fundándose en las fuentes romanas, darán lugar a la doctrina tradicional en la materia ${ }^{42}$. En definitiva, en palabras de Bacache-Gibeili, "en la concepción tradicional, [en Francia] la culpa contenía dos elementos, uno objetivo, consistente en la violación de una obligación o de un deber preexistente, y un elemento subjetivo, concerniente a las aptitudes

\footnotetext{
37 Bacache-Gibeil (2007), p. 7 ss. Véase Domat (1697), pp. 113 ss.

38 En tal sentido, Pothier afirmaba expresamente que de la propia definición de delito y cuasidelito resulta que los carentes de razón no son capaces de ellos. POtHIER (2007), p. 69.

39 En esta parte, el análisis de Delvincourt sigue sin variaciones al efectuado por Pothier, a cuya obra reenvía para profundizaciones sobre el punto. Véase Delvincourt (1813), tomo II, p. 748.

40 Delvincourt (1813), tomo II, p. 748. Traducción libre.

${ }^{41}$ MarCadé (1889), pp. 294-295. Traducción libre. El mismo autor luego afirma "C'est ainsi, comme nous l'avons dit déjà, que la construction que j'ai faite dans les conditions voulues par la loi, bien qu'elle vienne masquer toutes vos fenêtres, ne m'oblige à rien, parce que, si ce fait préjudiciable est volontaire, il n'est pas illicite; c'est ainsi également que l'acte d'un fou qui vient couper vos arbres ne l'oblige pas non plus, parce que, si ce fait préjudiciable est illicite, il n'est pas volontaire. Dans ces cas et autres semblables, il n'y a pas faute, et la faute est indispensable pour faire naître l'obligation de réparer le dommage causé". MARCADÉ (1889), p. 296.

42 A modo de ejemplo, véase Laurent (1876), pp. 471 ss.; Fromageot (1891), p. 59 ss.; LuCAsievicz (1900), pp. 138 ss. Agradezco al árbitro anónimo de la Revista lus et Praxis, por la indicación de algunos de estos autores.
} 
sicológicas del autor para comprender el alcance de sus actos y para discernir las consecuencias" ${ }^{\prime 3}$.

Sin embargo, dicha concepción varió significativamente, al punto que hoy en día "solamente subsiste el primer elemento, el segundo fue progresivamente eliminado por la ley y la jurisprudencia, luego de haber sido cuestionado por la doctrina" ${ }^{44}$. En efecto, atendidas la masificación de los accidentes laborales y de transporte, así como las dificultades probatorias de la culpa ${ }^{45}$, a fines del siglo XIX, surge tanto en Francia como en Italia un cuestionamiento a la culpa como fundamento de la responsabilidad civil y toma terreno la idea de sustituirla por la noción de riesgo ${ }^{46}$, postulando que bastaría la sola causalidad para atribuir responsabilidad ${ }^{47}$. Se origina así un arduo debate que se resume en las preguntas "¿se es responsable desde que se actúa? O, por el contrario, ¿sólo se es responsable desde que se ha obrado de modo diverso al que debería haberse obrado? ¿Exige la responsabilidad civil una apreciación de la conducta del autor del daño, esto es, que el mismo hubiera incurrido en culpa?"48. Los partidarios de la teoría del riesgo, naturalmente, dan una respuesta negativa a esta última pregunta, afirmando que la responsabilidad surge desde el momento de la actuación dañina, pues es necesario proteger a las víctimas. Esta visión de la responsabilidad civil fue contrarrestada recurriendo a la ampliación del concepto de culpa, en este escenario se inserta el Tratado teórico y práctico de responsabilidad civil, de los Mazeaud, quienes darían la pincelada definitiva a la

43 BACACHE-GiBeILI (2007), p. 123, traducción libre. En efecto, así lo afirmaba expresamente René
Demogue, quien, a pesar de reconocer que para algunos autores la faute comprendía sólo uno de los
dos elementos, a la pregunta ¿cuándo hay faute?, responde: "Deux conditions, dapres la Jurisprudence,
semblent indispensables: I'une objctive et l'autre subjective; une atteinte au droit et le fait d'avoir' aperçu
or pu percevoir que l'on portait atteinte au droit d'autrui". DemoGuE (1923), tomo III, p. 367 . El elemento
subjetivo, el autor lo conecta con el haber previsto o tener la posibilidad de prever el resultado dañino
(ídem, pp. 408 ss.), de manera que, aunque no lo diga expresamente, se excluye la responsabilidad de
todos quienes carecen de la aptitud psicológica para prever las consecuencias de sus actos.

44 Bacache-Gibeilı (2007), p. 123, traducción libre.

45 Como explica Fernández, la evolución desde una noción subjetiva a una noción objetiva de culpa, va de la mano de la industrialización y el desarrollo tecnológico de la sociedad. Fernández (2005), pp. 237 ss. En el mismo sentido BaCAChe-Gibelı (2007), p. 10.

46 La discusión en torno al argumento es bastante conocida en la doctrina y se encuentra magistralmente resumida en la obra de los Mazeaud, como antesala a la construcción de la noción objetiva de culpa, obra a la cual se reenvía para mayores profundizaciones en la doctrina francesa anterior a ella. MAZEAUD et al. (1962), pp. 7 ss.; VINEY (2007), pp. 115-116. En Chile, un temprano y muy buen resumen de las diversas opiniones de los autores franceses en este sentido, puede verse en EscríBAR (1923), pp. 17 ss.

47 Saleilles (1897), 90 pp. En sentido escéptico y con abundantes citas doctrinarias, véase Planiol (1917), pp. 285 ss.

48 Mazeaud et al. (1962), p. 7. 
concepción objetiva de la culpa ${ }^{49}$. En efecto, estos autores rechazaron rotundamente la doctrina del riesgo, afirmando que "el problema de la responsabilidad civil es infinitamente más vasto: el interés social no siempre consiste en proteger a las víctimas; también puede ser asegurar la libre actividad de los individuos, no paralizarlos haciendo pesar sobre ellos la amenaza de una responsabilidad susceptible de alcanzarlos aun cuando su conducta fuere irreprochable ${ }^{\prime \prime 50}$. En consecuencia, afirman, "la culpa debe ser mantenida como condición y fundamento de la responsabilidad civil. Tal es el principio: nada de responsabilidad sin culpa"; ello sin perjuicio de que situaciones particulares, como los accidentes del trabajo, admitan una excepción ${ }^{51}$. Sin embargo, según destaca Viney ${ }^{52}$, lo cierto es que los Mazeud mantenían también una actitud favorable a las víctimas. La conciliación de estas ideas se logró a través de la noción de culpa, a la cual privaron de todo elemento moral o sicológico, excluyendo la posibilidad de apreciar cualquier circunstancia interna del autor del daño, incluida la capacidad de discernimiento. Al efecto señalan: "la consideración de las circunstancias "internas" supone admitir la apreciación in concreto, exigir la culpabilidad, confundir la responsabilidad penal con la civil, el castigo con la reparación del daño. Entonces, debe afirmarse que el tipo de comparación debe ser ubicado en las circunstancias "externas", no en las circunstancias "internas" en las que se encontraba el demandado" 53 . Agregando que, "del hecho de que el tipo de comparación deba ser ubicado sólo en las circunstancias externas en las que se encontraba el demandado resulta que el infans y el demente pueden ser tenidos por civilmente responsables" ${ }^{\prime 54}$. De esta manera se llega a la configuración de una noción completamente objetiva de culpa ${ }^{55}$.

La noción objetiva de culpa influenció de tal manera al Derecho francés que la Ley de 3 de enero de 1968, que reformó el derecho de los incapaces mayores, introdujo en el Code el artículo 489-2, contemplando expresamente la

\footnotetext{
49 Para la preparación de este trabajo se utilizó la traducción de Luis Alcalá Zamora, publicada en 1962. Para verificar la evolución y consagración de la teoría en los mismos autores, se consultó la $8^{\mathrm{a}}$ ed. de la obra Leçons de droit civil, escrita por los Mazeaud junto a Chabas, quien ha participado también en ediciones posteriores del Tratado de Responsabilidad Civil. Véase MAZEAUD et alt. (1991), tomo II, vol. 1. 1354 pp.

50 Mazeaud et al. (1962), p. 10.

51 Mazeaud et al. (1962), pp. 12-13.

52 VINEY (2007), pp. 115 ss.

53 La reconstrucción in extenso de este razonamiento puede verse en, MAZEAUD et al. (1962), p. 36.

54 Mazeaud et al. (1962), p. 37.

55 En contra de tal construcción pueden verse las ideas de Josserand, quien, citando a Pothier, afirma que la tradición es clara es sostener que infantes y dementes no pueden incurrir en culpa. JOSSERAND (1939), p. 273.
} 
responsabilidad civil de los dementes ${ }^{56}$. Si bien esta ley se limitó a los dementes, inmediatamente surgieron voces que proponían la extensión, por analogía, a los niños. La extensión no fue pacífica, sin embargo, el 9 de mayo de 1984, la Corte de Casación resolvió que la responsabilidad del niño, por hecho propio o de las cosas, no exigía la prueba del discernimiento ${ }^{57}$. Esta decisión significó un vuelco definitivo el sistema de responsabilidad civil francés. En lo que aquí respecta, significó que dementes e infantes sean responsables por sus hechos frente a terceros y que su culpa sea considerada para efectos de la reducción de la indemnización por culpa de la víctima ${ }^{58}$. Con todo, cabe señalar que esta última solución ha sido objeto de duras críticas en la doctrina francesa ${ }^{59}$. Así, no han faltado autores que sostengan que la noción objetiva de culpa, que en principio tenía por objeto proteger a las víctimas, terminó por volverse en contra de ellas, llegando incluso a proponer la acogida de dos nociones de culpa: una objetiva para el agente y otra subjetiva para la víctima ${ }^{60}$.

En síntesis, la preocupación por la posición de las víctimas ha llevado en más de una oportunidad a poner en crisis la noción de culpa como fundamento de la responsabilidad civil, el resultado más reciente de esta crisis ha sido su objetivación, que la privó de uno de sus elementos: la posibilidad de actuar de

\footnotetext{
56 En la numeración actualmente vigente del Code Civil, el artículo 489-2 corresponde al artículo 414-3. Modificación introducida por la Ley № 2007-308 de 5 de marzo de 2007, en vigencia desde el 1 de enero de 2009.
}

57 Chabas (2009), p, 25; Viney y Jourdain (2006), pp. 344. Lo cierto es que la doctrina de la culpa objetiva nunca distinguió entre dementes y niños, al contrario, desde el principio sus conclusiones se hicieron extensivas también a estos. Así puede observarse en un artículo de 1957, publicado en la Revista Trimestral de Derecho Civil. Blanc-Jouvan (1957), pp. 28-60, especialmente pp. 51 ss.

58 En efecto, para los Mazeaud una de las ventajas de que la culpa fuera el fundamento de la responsabilidad radicaba precisamente en que en que ello "no solamente implica que el demandado haya cometido culpa, sino también que la culpa de la víctima sea tomada en consideración para moderar la responsabilidad del demandado o para descargarlo de toda responsabilidad; la víctima debería soportar las consecuencias de su propia culpa MAZEAud et al. (1962), p. 13.

59 VINEY y JOURDAIN (2006), pp. 344 ss. Es interesante notar que la crítica proviene incluso de uno de los
autores que ha participado en las nuevas ediciones del Tratado, esto es, Chabas. En efecto, en sentido
crítico se pronunció este autor en la exposición que hiciera en las Jornadas de Derecho Civil chilenas del
año 2010 . Véase a la versión escrita de esta ponencia en CHABAS (2011), pp. 469-473. En todo caso, los
extremos a que llevó la noción objetiva de culpa han sido en cierta medida morigerados por la Ley de 5
de julio de 1985 , llamada "ley Badinter", que regula la responsabilidad civil derivada de los accidentes
de tránsito y los seguros obligatorios asociados a ellos. En virtud de esta ley, las víctimas menores
de 16 años o mayores de 70 , así como aquellas afectas a más de un $80 \%$ de discapacidad, tendrán
derecho resarcimiento integral del daño corporal, incluso cuando hayan contribuido culpablemente a
su producción, salvo que se hayan intencionalmente buscado la producción del daño.

60 En este sentido, BACACHE-GIBEIL (2007), pp. 127 ss. Cabe señalar que una distinción de esta naturaleza ha tenido lugar tradicionalmente en el Common Law estadounidense, a propósito de los enfermos mentales. Terry (1915), p. 47; ZeNO-ZenCOVICH (1986), p. 8; YáÑeZ (2011), p. 1315. 
modo diferente, según la cual para incurrir en culpa es necesaria una actuación libre, voluntaria y consciente.

\section{La noción objetiva de culpa y la necesaria independización de la culpa y la imputabilidad como elementos de la responsabilidad civil. El ejemplo de Italia}

A partir de la obra de los Mazeaud y su circulación, en Derecho comparado pueden advertirse dos nociones de culpa, una noción subjetiva y otra objetiva. ${ }^{61}$ La noción subjetiva corresponde al concepto tradicional de origen romano, que incluye la aptitud del sujeto para advertir el riesgo y comportarse en modo diferente, aunque esta aptitud se limite a la posibilidad (teórica) de abstenerse de actuar. La noción objetiva, en cambio, se funda en la sola disconformidad entre la conducta ideal (estándar) y la conducta concreta (comportamiento efectivo) del sujeto en cuestión. El resultado práctico de introducir una noción objetiva de culpa es que todas las personas pueden incurrir en ella, incluso aquellos que no están en condiciones de adaptar su conducta a las circunstancias, por carecer de discernimiento.

En un país, como Francia, en que el Código Civil carece de reglas de capacidad extracontractual, la adopción de la noción objetiva de culpa implica simplemente una nueva visión de la responsabilidad civil, sin mayores dificultades sistemáticas. En cambio, en países que sí contienen dichas reglas la situación se complica, pues la recepción de tal concepto supone asignar a las reglas de capacidad un rol independiente de la culpa. Un ejemplo de esta situación puede verse en Italia, donde parte de la doctrina aboga por la noción objetiva de culpa y, en consecuencia, se discute sobre el rol de la imputabilidad en el juicio de responsabilidad civil.

Como es sabido, desde su unificación, Italia ha tenido dos Códigos Civiles, el primero, de 1865, fuertemente influenciado por el Código francés y el segundo, de 1942, que conserva mucho del anterior, pero que tuvo recibió también influencia germánica. El Código de 1865 no contenía ninguna norma relativa a la imputabilidad; sin embargo, la doctrina y jurisprudencia italiana no dudaban en que ella era una exigencia de la culpa ${ }^{62}$, pues no podían incurrir en esta quienes carecieran de discernimiento ${ }^{63}$. Al igual que en Francia, esta

\footnotetext{
${ }^{61}$ En términos explícitos, esta distinción puede verse en De SaLAS (2003), pp. 81 ss.

62 En todo caso, esta exigencia no siempre se plantea en los mismos términos. Para algunos autores, la imputabilidad constituye un "presupuesto" necesario, pero independiente de la noción de culpa; para otros, en cambio, constituye un "elemento" o "requisito" de la culpa. Sobre el punto véase MAIORCA, (1960), pp. 547 ss.

63 Por todos, Chironi (2012), pp. 312 ss.; Momigliano (1937), pp. 193-255.
} 
visión fue puesta en crisis por los partidarios del riesgo como fundamento de la responsabilidad civil ${ }^{64}$; sin embargo, en la redacción del nuevo código, prevaleció la visión romano-germánica, que pone a la base del ilícito a la culpa y exige imputabilidad. De esta manera, en el código de 1942 se incorporó el artículo 2046, que regula la imputabilidad del hecho dañino y establece que no son responsables de las consecuencias del hecho dañino las personas que, al momento del hecho, no tenían la capacidad de entender o querer, a menos que el estado de incapacidad derive de su culpa ${ }^{65}$. Sin perjuicio de que bajo ciertas circunstancias los inimputables pueden ser obligados a pagar una indemnización ad aequitatem, en los términos del artículo 2047.

Según la interpretación tradicional, el artículo 2046 debe entenderse en el sentido que las personas carentes de discernimiento no pueden incurrir en culpa $^{66}$; por su parte, la disposición del artículo 2047 constituiría una excepción a la regla general de la responsabilidad por culpa, constituyendo una suerte de responsabilidad objetiva. Sin embargo, parte de la doctrina italiana moderna se ha inclinado por acoger la noción objetiva de culpa, lo que ha puesto en crisis la colocación sistemática de las normas recién referidas y, en particular, ha generado una discusión en torno al rol de la imputabilidad en la estructura de la responsabilidad civil ${ }^{67}$. Así, para alguna doctrina se ha producido una des-

64 Según relata Alpa, al igual que Francia, a finales del s. XIX se instaló en Italia el debate en torno al rol de la culpa en la responsabilidad civil. Al efecto señala que "Il grande dibattito che si instaura a fine secolo (...) sta proprio qui: nella omnnipervasivita del principio della colpa e nelle prime teorizzazioni della responsahilita oggettiva. I grandi giuristi dell'epoca sono a favore di una diarchia: si giustifica l'ingresso della responsabilita incolpevole per ragioni di ordine pubblico e, oggi si direbbe, di solidarieta sociale. L'avvento della societa industriale, con il proliferare dei danni «anonimi», I'esigenza di offrire un risarcimento al malcapitato che non e in grado di individuare la propria colpa, l'esigenza di introdurre le (prime) forme di assistenza sociale nel mondo del lavoro militano tutte a favore delle tesi anti-colpevoliste. Le pagine di Barassi, Cogliolo, Coviello, Gabba, Chironi, Venezian sono tutte in questo senso". Alpa (1990), p. 147.

65 Art. 2046 Imputabilità del fatto dannoso. "Non risponde delle conseguenze dal fatto dannoso chi non aveva la capacità d'intendere o di volere al momento in cui lo ha commesso, a meno che lo stato d'incapacità derivi da sua colpa".

66 En este sentido, afirma De Cupis, "el precepto requiere para que el sujeto responda de las consecuencias del hecho dañoso, que tenga la capacidad de entender o de querer en el momento en que lo ha cometido, o bien tenga la aptitud para ser culpable. (...) La culpa es un estado de ánimo reprobablemente disforme del que suele producirse en los individuos dispuestos a evitar los daños. Los incapaces de entender o querer son, naturalmente, ineptos para discernir y valorar las consecuencias de las propias acciones, $y$, como tales, son incapaces de incurrir en culpa". DE CUPIS (1975), pp. 216-217.

67 Las distintas opiniones en torno a este punto pueden verse en: D'AGATA (2014), pp. 11 ss. Asimismo, un extenso análisis de la doctrina italiana en torno a esta problemática, asociada a los problemas que, a su vez, se han generado en Perú, puede verse en LEón (2005), pp. 45. 
vinculación entre los conceptos de culpa e imputabilidad. En efecto, atendida la expresa disposición normativa, la doctrina italiana partidaria de la noción objetiva de culpa ha debido hacerse cargo de la imputabilidad como requisito de la responsabilidad civil y, para mantener la coherencia, ha concluido que culpa e imputabilidad constituyen elementos independientes, que guardan entre sí completa autonomía ${ }^{68}$. En esta línea de pensamiento se ha llegado a sostener que la incapacidad constituye una causal de exención de responsabilidad, pero que no excluye la culpa. En este sentido, afirma Bianca que "la inimputabilidad del incapaz se fundaba antiguamente en la noción subjetiva de culpa. Entendida como una reprochable actitud sicológica, era oportuno deducir que no puede incurrir en culpa quien carece de discernimiento. Construida la noción objetiva de culpa, como disconformidad con un modelo objetivo de conducta diligente, debe admitirse que incluso el comportamiento del incapaz es susceptible de ser calificado de culpable" ${ }^{\prime 69}$. De ahí que la razón de su ausencia de responsabilidad no radique en la ausencia de culpa, sino en la existencia de una eximente personal de responsabilidad. ${ }^{70}$

En lo que aquí respecta, esta última visión de la imputabilidad tiene algunas consecuencias prácticas importantes, a saber, (i) permite la aplicación de la reducción por culpa de la víctima a las víctimas incapaces, sin necesidad de afirmar categóricamente que se trata de una cuestión exclusivamente causal, ni de construir dos conceptos de culpa, uno objetivo para la víctima y uno subjetivo para el agente ${ }^{71}$; y (ii) la imputabilidad se eleva a requisito de la responsabilidad civil en general, aplicable también en las hipótesis de responsabilidad objetiva. Nótese que esta última consecuencia encierra una gran paradoja, pues la noción objetiva de culpa surge precisamente para ampliar el círculo de aplicación de la responsabilidad civil y, al establecer la imputabilidad como requisito autónomo, se termina por estrecharlo. En efecto, en un sistema subjetivo de responsabilidad, quienes no son capaces de culpa son perfectamente responsables en sede objetiva, al tornarse la imputabilidad un elemento independiente de la responsabilidad civil, ello no es posible.

\footnotetext{
${ }^{68}$ En este sentido se ha dicho que "In tal modo -quando si valuta la colpa in senso oggettivo- si svincola quindi il comportamento da un giudizio morale e soggettivo, tendendo così verso una separazione del concetto di imputabilità e colpevolezza, che giunge fino ad una piena autonomía delle due figure". BONOMO (2012), p. 35.

69 BiAnCA (2004), pp. 655-656. Traducción libre.

70 BIANCA (2004), pp. 655-656. Traducción libre.

71 Esta solución se desprende de la decisión de la Cassazione Civile, Sez. III, 10 de febrero de 2005, n. 2704, comentario en MICARI (2005), pp. 1175 ss.
} 


\section{La supervivencia de la relación entre culpa e imputabilidad en España, en los Principios de Europeos de Responsabilidad Extracontractual y en Alemania}

A pesar de su expansión, la noción objetiva de culpa no ha llegado a eliminar totalmente la relación entre culpa e imputabilidad. En lo que sigue, se ofrecen tres ejemplos de ordenamientos en que, con mayor o menor medida, puede observarse esta subsistencia: (i) España; (ii) los Principios Europeos de Responsabilidad Extracontractual (PETL) y (iii) Alemania.

En España, el Código Civil no contiene una regla relativa a la incapacidad para responder extracontractualmente. Este silencio legislativo ha sido colmado por la doctrina y la jurisprudencia, señalando que los inimputables no responden civilmente, pues son incapaces de culpa ${ }^{72}$. En este sentido, bajo la rúbrica "las condiciones personales de imputabilidad subjetiva: la capacidad de discernimiento o capacidad de culpa", afirma Díez-Picazo: "para que pueda formularse un juicio de culpabilidad es preciso que en el sujeto concurran las condiciones necesarias para ello y, en especial, la denominada capacidad de discernimiento o capacidad de culpa" ${ }^{\prime 73}$. La contrapartida de esta afirmación es que no existe inconveniente para que los inimputables sean considerados responsables en hipótesis de responsabilidad objetiva, en que se prescinde de la culpa ${ }^{74}$. La concepción subjetiva de culpa se refleja en la llamada culpa concurrente de las víctimas inimputables, pues se discute respecto de si ella constituye técnicamente culpa, en cuyo caso no es procedente la institución, o bien se trata de un sentido no técnico de culpa, en cuyo caso sí los es. La opinión mayoritaria se ha inclinado por la primera opción ${ }^{75}$.

Según los PETL, "una persona responde con base en la culpa por la violación intencional o negligente del estándar de conducta exigible" (art. 4:101). Esta definición acoge un esquema totalmente objetivo de culpa, aludiendo exclusivamente a un estándar de conducta, sin embargo, la disposición siguiente introduce algunos elementos subjetivos, al afirmar que el estándar de conducta "puede adaptarse cuando debido a la edad, a la discapacidad física o psíquica o a circunstancias extraordinarias no sea exigible que la persona de que se trate lo cumpla". Si bien la norma alude a la adaptación del estándar de conducta

\footnotetext{
72 Para una panorámica general del derecho español en torno al punto, véase Gómez Calle (1992), pp. 23 ss.; Martín-Casals (2006), pp. 369 ss.; Seuba et al. (2004), 28 pp.

73 Díez-Picazo (2011), p. 278; en el mismo sentido, Reglero y Bustos (2014), pp. 303 ss.; para un estudio profundizado sobre el problema de la imputabilidad en el Derecho español, López (2001), pp. 167 ss.; De Salas (2003), pp. 70 ss.

74 Martín-Casals (2006), p. 377.

75 Por todos Medina (2003), pp. 297 ss.; Martín-Casals et al. (2007), p. 235.
} 
y no al hecho de que los incapaces no son susceptibles de incurrir en ella, lo cierto es que, según indican los comentarios de este segundo artículo, él fue introducido para morigerar los efectos del concepto puramente objetivo de culpa contemplado en el artículo precedente, con el fin de evitar que, en ciertos casos, la responsabilidad subjetiva se transformara en objetiva; agregando que esta situación es intrínseca al concepto de culpa, al punto que no constituye una defensa autónoma ${ }^{76}$. Estas consideraciones evidencian la relación que, en concepto de la posición finalmente dominante en el $\mathrm{Grupo}^{77}$, existe entre culpa e inimputabilidad. En efecto, en la medida que quienes carecen de discernimiento no podrán ser juzgados con un estándar objetivo de conducta, sino que tendrá que tenerse en consideración su situación particular, la falta de discernimiento será una causal de exclusión de culpa y no en general de responsabilidad.

En Alemania, en la versión original del BGB, las reglas sobre imputabilidad eran las siguientes: según el parágrafo 827, todavía vigente, las personas privadas de razón (a menos que esta privación se deba a su negligencia) no son responsables por los daños que causen. A su vez, el parágrafo 828 establecía que tampoco respondían los menores de siete, ni aquellos que habiendo cumplido siete, no hubieren alcanzado la mayoría de edad, salvo que se comprobara que habían actuado con discernimiento. Finalmente, según el parágrafo 829, quienes no responden en virtud de las reglas anteriores, pueden ser obligados a pagar una indemnización ad aequitatem, bajo ciertos supuestos. En la interpretación de la doctrina, estas normas obedecen a que por regla general, la responsabilidad civil exige la culpa que, a su vez, exige discernimiento, el cual se traduce en la capacidad para reconocer el injusto de su actuar y comportarse de acuerdo a este entendimiento ${ }^{78}$. En otras palabras, se exige que las

\footnotetext{
76 European Tort Group (2005), p. 79.

77 A juzgar por los duros dichos de Martin-Casals, que la califica de "victoria pírrica" de los sostenedores de la visión subjetiva, Ilegar a esta conclusión no debió haber sido fácil. MARTíN-CASALS (2005), p. 19; una primera aproximación a los "Principios de Derecho europeo de la responsabilidad civil", en Martín-Casals (2005), p. 13.

78 Kozıol (2012), p. 200. En ese sentido afirma Larenz: "hablamos de conducta "culposa" cuando al agente le alcanza personalmente un reproche. Esta censura se funda en que en el caso concreto hubiera debido o podido obrar de otra forma en que en el caso concreto hubiera debido o podido obrar de otra forma, en que, por tanto, se ha conducido injustamente cuando hubiera sido posible conducirse rectamente con la necesaria diligencia, o atención o "buena voluntad". La libertad de poder obrar de otra forma y la desconsideración que, a pesar de ello, se muestra hacia la norma, son los elementos de toda inculpación obligacional". (Cfr. LARenz (1958), p. 280. Luego, a propósito de la "capacidad para ser responsable por dolo o culpa, añade: "el deudor responde por dolo o por culpa únicamente cuando al tiempo de la acción posee la inteligencia necesaria para una razonable determinación de la voluntad, que la ley presupone, en general, en un hombre sano de mente y no inexperto". LARENZ (1958), p. 291.
} 
personas tengan la capacidad para actuar razonablemente ${ }^{79}$. De esta manera, los parágrafos 827 y 828 resultan de la aplicación de la regla general, mientras que el parágrafo 829 constituye una excepción a esa regla; una hipótesis de responsabilidad sin culpa, fundada en la equidad ${ }^{80}$. En consecuencia, existiría una intrínseca relación entre culpa e imputabilidad. Como contrapartida, tales reglas no se aplicarían en hipótesis de responsabilidad objetiva, pues, en estos casos, al prescindirse de la culpa, se prescinde también del juicio de imputabilidad ${ }^{81}$.

El panorama anterior se ha visto levemente transformado por la modificación introducida al parágrafo 828, el 19 de julio de 200282. Esta normativa le introdujo un inciso segundo al citado artículo, según el cual, los menores que han cumplido siete años, pero no han cumplido diez, tampoco responden de los daños causados a terceros en accidentes de tránsito, a menos que hayan actuado intencionalmente, desde los diez años es necesario el juicio de discernimiento ${ }^{83}$. Este inciso pone en crisis la relación entre imputabilidad porque expresamente excluye la responsabilidad de los menores sin discernimiento por los daños causados en accidentes de tránsito, en circunstancias que en Alemania la responsabilidad en ese tipo de accidentes es objetiva ${ }^{84}$. Por otro lado, un sector de la doctrina alemana ha propuesto que, cuando menos en el caso de los niños, las reglas sobre imputabilidad deben analógicamente

79 A minor has the capacity to act reasonably if his intellectual maturity allows him to understand that he acted unlawfully and that this unlawful conduct may result in civil liability. WAGNER (2007) p. 218.

80 WAGNER (2007) p. 222.

81 En este sentido se ha dicho que "as strict liability follows a no-fault concept, the rules on capacity to act reasonably (\$ 828 BGB) are not directly applicable". WAGNER (2007), p. 227.

82 Zweites Gesetz. Zur Änderung schadensersatzrechtlicher Vorschriften, artículo $3^{\circ}$. Disponible en http://www.bgbl.de/xaver/bgbl/start.xav? start=\%2 F\%2F*\%5B\%40attr id\%3D\%27bgbl102s2674.pdf\%27\%5D\#_bgbl_\%2F\%2F*\%5B\%40attr_id\%3D\%27bgbl102s2674. pdf\%27\%5D_1468278156786 [Consultado 11 de julio de 2016].

83 El texto actual del parágrafo es el siguiente:

Section 828 Minors

(1) A person who has not reached the age of seven is not responsible for damage caused to another person.

(2) A person who has reached the age of seven but not the age of ten is not responsible for damage that he inflicts on another party in an accident involving a motor vehicle, a railway or a suspension railway. This does not apply if he intentionally caused the injury.

(3) A person who has not yet reached the age of eighteen is, to the extent that his responsibility is not excluded under subsection (1) or (2), not responsible for damage he inflicts on another person if, when committing the damaging act, he does not have the insight required to recognise his responsibility". Traducción proporcionada por el Ministerio Federal de Justicia y Protección del Consumidor, Alemania. Versión disponible en: http://www.gesetze-im-internet.de/englisch_bgb/ [Consultado el 11 de julio de 2016].

84 MARKESINIS Y UnBerATH (2002), pp. 728 ss. 
aplicarse en casos de responsabilidad objetiva, pues se entiende que los niños requieren protección también en estos $\operatorname{casos}^{85}$. Estas consideraciones ponen en crisis la idea de que la imputabilidad está estrechamente ligada con la culpa, sin embargo, ambos conceptos no han llegado escindirse ${ }^{86}$. Por lo demás, según reconoce la doctrina alemana, el principal objetivo de la regla en cuestión es impedir que los automovilistas opongan la culpa del niño como concausa del accidente ${ }^{87}$. En efecto, respecto de la responsabilidad de los niños, la regla tiene baja aplicación práctica, toda vez que la jurisprudencia ha resuelto que ella alude a los accidentes de tránsito provocados por los niños en vehículos (excluidas las bicicletas) en movimiento ${ }^{88}$ y, dado que ellos no están autorizados para conducir, los accidentes que ellos pueden provocar son mínimos ${ }^{89}$. Por el contrario, desde la perspectiva de la víctima, tiene gran relevancia, pues, atendido que el parágrafo 828 rige también cuando se considera la culpa de la víctima ${ }^{90}$, al establecer que los niños no son responsables frente a terceros, automáticamente los automovilistas quedan impedidos de oponer su culpa concurrente como concausa del accidente. Así las cosas, la referida regla está en línea con la Ilamada "ley Badinter" de la legislación francesa, que lo que busca es proteger a las víctimas de los accidentes de tránsito ${ }^{91}$.

En resumen, los tres ejemplos normativos analizados, PETL, España y Alemania, en mayor o menor medida, conservan la relación entre culpa e imputabilidad. Lo cual se refleja en el hecho de que la falta de discernimiento excluye responsabilidad cuando se esta se funda en la culpa, pero no necesariamente cuando la responsabilidad se funda en un criterio de atribución diferente, como es el riesgo o en la equidad, en el caso del parágrafo 829 BGB.

85 WaGner (2007), pp. 227 ss.

86 La doctrina continúa a colocar a la capacidad como un componente de la culpa. Véase KozıOL (2012), p. 200.

87 Magnus (2003), p. 8; Schiemman (2013), p. 2822.

88 BGH (2004), Urteil vom 30. November 2004 - VI ZR 335/03. Disponible en http://lorenz.userweb. mwn.de/urteile/vizr335_03.htm [Consultado el 11 de julio de 2016].

89 Por otro lado, se excluyen los daños causados intencionalmente por estos menores, por ejemplo, que lancen piedras a los automovilistas. MAGNus (2003), p. 8.

90 En Alemania rige la Ilamada "teoría del espejo", en consecuencia, "a child under the age of seven cannot be held accountable for contributory negligence, $\S 828$ subs. 1 BGB. This minimum age is raised to ten years if the damage was sustained in an accident involving a motor vehicle, a railway, or a cable car, $\S 828$ subs. 2 cl. 1 BGB. If the child is older than seven or ten, respectively, but younger than eighteen years, the finding of contributory negligence depends on the child's capacity to understand his responsibilities, $\$ 828$ subs. 3 BGB". WAGNER (2007), p. 125.

91 Véase supra, nota 49. En el mismo sentido, Magnus (2003), p. 8. 


\section{La Imputabilidad en Chile}

\section{Concepción subjetiva de culpa en el Código de Bello. La visión doctrinaria reciente}

Como es sabido, a diferencia del Código Civil francés, el Código Civil chileno incluyó expresamente una regla sobre la capacidad para cometer delitos civiles, el artículo 2319, que a la sazón señala: "No son capaces de delito o cuasidelito los menores de siete años, ni los dementes; pero serán responsables de los daños causados por ellos las personas a cuyo cargo estén, si pudiere imputárseles negligencia. //Queda a la prudencia del juez determinar si el menor de diez años ha cometido el delito o cuasidelito sin discernimiento; y en este caso se seguirá la regla del inciso anterior".

A juzgar por el texto de la norma, su fuente directa debió haber sido Pothier, pues ella constituye prácticamente una paráfrasis del $\S 118$ del Tratado de las Obligaciones, donde el afirma: "resulta de la definición que hemos dado de los delitos y cuasidelitos que solo las personas dotadas de razón son capaces de cometerlos, pues los que la tengan, como los niños o los insensatos, no son capaces de malignidad no de imprudencia. Es por esto que si un niño o un loco hace alguna cosa que cause daño a alguien no resulta obligación ninguna de la persona de este niño o de este loco, pues lo que han hecho no es un delito, ni un cuasidelito, por lo mismo que no hay imprudencia, ni malignidad, de que no son susceptibles dicha clase de personas (sic). // No se puede definir precisamente la edad en que los hombres tienen el uso de la razón, y por consiguiente son capaces de malignidad, gozando de ella unos antes que otros, así es que hay que estimar la cuestión según las circunstancias, pero desde que una persona tiene el uso de razón, y que percibe en el hecho por el cual ha causado daño a otro, reflexión o malignidad, el hecho es un delito; y la persona que lo ha cometido, bien que no haya alcanzado todavía la edad de pubertad, contrata la obligación de reparar el daño causado. De donde nace esta máxima: Neminem in delictis aetas excusat. La imprudencia se excusa mucho más fácilmente en los jóvenes" ${ }^{\prime \prime 2}$. Acto seguido, continúa el señalando las razones por las cuales los interdictos por disipación sí son capaces de delito, tal y como se desprende del artículo, que solo alude a infantes y dementes ${ }^{93}$.

Atendido el tenor literal de la probable fuente de la norma, resulta claro que cuando el artículo 2319 excluye la responsabilidad de los incapaces lo hace porque estas personas no son susceptibles de incurrir en culpa. Es decir, para el codificador, la imputabilidad no es un elemento independiente de la

92 POthier (2007), pp. 69 ss.

93 POTHIER (2007), p. 70. 
responsabilidad civil, sino un componente de la culpa. Así lo ha entendido tradicionalmente la doctrina mayoritaria. Así, en opinión de Alessandri, la exigencia de capacidad delictual "es la consecuencia lógica del sistema adoptado por nuestro Código, según el cual la responsabilidad delictual o cuasidelictual no existe sino a condición de que el hecho u omisión perjudicial provenga de culpa o dolo de su autor, y una y otro suponen voluntad"94. Igualmente Meza Barros, para quien, "como consecuencia lógica del sistema subjetivo que el Código adopta, es condición esencial de la responsabilidad que el autor del delito o cuasidelito tenga suficiente discernimiento"95. A su vez, Tapia Suárez afirma que "en realidad, la noción de imputabilidad va subentendida en el elemento culpa, que ya hemos estudiado, el que no podría existir sin aquella", "(...) Para que un hecho sea culpable o doloso es menester que sea imputable a su autor, esto es, que al ejecutarlo este último haya obrado con la voluntad y el razonamiento necesarios, ya que, de acuerdo con la teoría clásica, no puede aceptarse que incurra en dolo o culpa el individuo que no tiene el discernimiento suficiente para darse cuenta de las consecuencia de sus actos" ${ }^{\prime \prime 6}$. Categórico en este sentido, y poniendo de presente el hecho de que hay opiniones disidentes, Domínguez Águila sostiene: "bajo la idea de imputabilidad -considerada por algunos como un elemento independiente- o de capacidad, se toma en consideración el estado mental del hechor, (por ej. En el art. 2319) incluso por aquellas concepciones más técnicas de culpa como la normativa. Un demente jamás podría responder por su culpa, porque la idea de apartamiento de la conducta diligente exige una voluntad y un criterio que permita conformarse al standard o modelo escogido o bien observar la conducta prevista como lícita y obligatoria por la ley"97. Otros autores, de forma más o menos expresa, se han pronunciado en idéntico sentido ${ }^{98}$.

Sin embargo, las categóricas afirmaciones anteriores se ven matizadas por la opinión de algunos autores que, sin detenerse mayormente sobre el punto, dan a entender que la imputabilidad es un elemento independiente de la responsabilidad civil, objetiva y por culpa ${ }^{99}$. Así, refiriéndose a la responsabilidad civil

94 AlesSANDRI (2004), p. 95.

95 MeZa (2010), p. 271.

96 TAPIA (2006), pp. 258-259 y pp. 168 y 169.

97 Domínguez (1989), p. 12.

98 En tal sentido puede verse Escribar (1923), pp. 17-34; Rosende (2000), pp. 277-297; Celis (2001), p. 74; TAPIA (2005), p. 282; Aedo (2006): pp. 186 y 187; Ramos (2006), pp. 42-48; Contreras (2009), pp. 193-194; Larroucau (2010), pp. 64 y 65; Rodríguez (2010), p. 186; Ruz (2011), p. 458.

99 Aunque sin ser enfáticos en este sentido, por el hecho de que ponen a la capacidad como un elemento de la responsabilidad civil, sin relacionarlo con la culpa, dicha idea se despende de BARCIA (2010), pp. 239 ss.; Abeliuk (2014), p. 284. 
en general, Corral afirma que "sólo las personas, actuando como tales, con su inteligencia y voluntad, pueden incurrir en responsabilidad", concluyendo que "la responsabilidad civil surge cuando puede verificarse un hecho voluntario, ilícito, imputable que ha sido la causa del daño a las personas" ${ }^{\prime 100}$. Acto seguido, el autor analiza la capacidad delictual como "un presupuesto común", entendemos, a ambas especies de responsabilidades, objetiva y por culpa ${ }^{101}$. Un poco más explícito al respecto ha sido Barros quien, en las notas sugeridas por la recensión de Rosenkrantz, afirma que "la responsabilidad civil, sea estricta o por negligencia, sólo tiene por común requisito subjetivo la capacidad para decidir un curso de acción, pero no le resultan relevantes las demás calificaciones de la acción que supone el juicio de reproche moral"102. Sin embargo, tal afirmación no se desprende con tanta claridad de la obra reseñada, donde el mismo autor afirma "en la responsabilidad por culpa, el discernimiento supone la capacidad para comprender que un acto es ilícito, así como una mínima aptitud de apreciación del riesgo"103, y luego, que "los incapaces no cometen acto ilícito cuando causan daño a un tercero, porque su conducta no puede ser objeto de un juicio de reproche, en atención a que no cumplen el requisito subjetivo de la responsabilidad"104. Ahora bien, relacionando ambos argumentos, que la capacidad es un presupuesto común a ambas clases de responsabilidad y el hecho de que ella supone ausencia de juicio de reproche, el autor estaría sosteniendo que la responsabilidad objetiva también se funda en un juicio de reproche de la conducta, algo que él mismo ha rechazado ${ }^{105}$.

\footnotetext{
100 Corral (2013), p. 100.

101 Corral (2013), p. 100. Comparte el análisis respecto a la postura de Hernán Corral Figueroa (2011), pp. 89-90.

102 Barros (2008), p. 312.

103 BarRos (2006), p. 67.

104 Barros (2006), p. 169. A su vez, en otra sede el mismo autor afirma, "en la medida que el juicio civil de culpabilidad supone discriminar la conducta correcta de la incorrecta, la culpa civil es esencialmente un juicio de ilicitud acerca de la conducta. // De este concepto se sigue que en el derecho civil el requisito de la culpa tiene una doble cara. Por un lado, expresa el principio de responsabilidad personal, porque sólo se responde de los daños imputables a una conducta que contraviene un deber de cuidado. Por otro lado, sin embargo, la imputación de la negligencia es objetiva, con la consecuencia de que el juicio de desvalor no recae en el sujeto, sino en su conducta, de modo que las peculiaridades subjetivas del agente son irrelevantes. En consecuencia, el juicio de culpabilidad civil no es un reproche moral al autor del daño, sino un criterio jurídico para hacerlo responsable de las consecuencias de su acción. Por eso, una vez cumplidas las condiciones subjetivas mínimas de la capacidad y de la libertad en la acción, el derecho civil trata al autor del daño como una persona que interactúa con los demás bajo un principio de igual responsabilidad, de modo que no puede excusarse alegando su propia inexperiencia o impericia". BARROS (2005), pp. 5 y 6.

105 A propósito de la responsabilidad estricta o por riesgo el mismo autor afirma "la responsabilidad por culpa tiene un elemento objetivo que la aleja del reproche personal; pero esa objetividad es
} 
Al margen de esas dos menciones expresas al rol de la imputabilidad como elemento independiente, no se encuentran en la doctrina nacional opiniones que hayan profundizado las consecuencias dogmáticas y prácticas de este nuevo rol. En efecto, nadie ha analizado el hecho de este rol significaría que los dementes e infantes sí incurren en culpa, pero que a su respecto opera una exención de responsabilidad. Por otro lado, nadie se ha preguntado qué función cumple el artículo 2319 en las hipótesis de responsabilidad objetiva que contempla el ordenamiento, cuestión fundamental cuando se trata de personas privadas sorpresivamente de razón ${ }^{106}$. Por consiguiente, no queda sino reconocer que el asunto no ha sido suficientemente tratado por la doctrina nacional y que, si bien se aprecia una tendencia a separar la imputabilidad de la culpa, dando a esta un cariz completamente objetivo, lo cierto es que las referencias han sido meramente tangenciales, sin que se haya llegado a analizar las consecuencias que de esta circunstancia se derivarían.

\section{Escaso tratamiento del rol de la imputabilidad en la jurisprudencia nacional.}

Como quedó demostrado con la somera mirada comparada efectuada en el capítulo anterior, la cuestión sobre si la imputabilidad forma parte de la culpa o es un elemento ajeno a ella varía dependiendo el ordenamiento jurídico en que nos situemos. Por otro lado, atendida la época de su redacción y las fuentes que le sirvieron de inspiración, no cabe duda que cuando el redactor del Código Civil sostuvo que había ciertas personas incapaces de delito, lo hacía en el entendido que estas personas no eran capaces de incurrir en culpa. De esta manera, cuando menos en su origen, el ordenamiento jurídico chileno está construido sobre la base de que la imputabilidad es parte de la culpa. A su vez, se ha evidenciado una tendencia hacia la objetivación del concepto de culpa, que coloca a la imputabilidad como elemento autónomo de la responsabilidad civil. Atendidos todos estos antecedentes, es necesario preguntarse si el ordenamiento jurídico chileno ha conservado la noción originaria de culpa o si, por el contrario, se ha producido una mutación, debido a un tránsito desde la noción subjetiva de

radicalizada en el caso de la responsabilidad estricta, porque ni siquiera requiere que la conducta sea objetivamente reprochable. Lo determinante es que se materialice un riesgo que está bajo el control de responsable". BARROS (2006), p. 445.

106 Podría perfectamente ocurrir que una persona, desarrollando lícitamente una actividad que genera responsabilidad objetiva (manejar residuos peligrosos en los términos de la reciente Ley № 20.920, por ejemplo), sufra una privación de razón que le induzca a causar daño. La pregunta es, ¿se aplica o no el artículo 2319? Si entendemos que la imputabilidad es un presupuesto de la responsabilidad civil en general, la respuesta es sí y, por tanto, la persona no responde. Si entendemos que es un componente o presupuesto de la culpa, la respuesta es no y, por tanto, la persona sí responde. 
culpa a hacia la noción objetiva y, de ser este el caso, cabe preguntarse ¿qué rol cumple la imputabilidad regulada en el artículo 2319 CC.? Atendido el escaso tratamiento doctrinario, una vía para responder esta pregunta sería el análisis jurisprudencial, pero lo cierto es que la jurisprudencia tampoco ha sido explicita sobre el punto, pues el asunto no ha sido directamente discutido en tribunales. Con todo, de algunas sentencias en que se alega la exposición imprudente de la víctima al daño, se desprende que los tribunales consideran a la capacidad como un componente de la culpa, asumiendo así una concepción subjetiva de esta. En efecto, los jueces niegan que los incapaces de cometer delito o cuasidelito puedan incurrir en la "imprudencia" aludida en el artículo 2330. En tal sentido, es posible observar los siguientes fallos:

(i) A propósito del accidente sufrido por un menor de catorce años de edad, en que los tribunales de instancia aplicaron el artículo 2330 y los demandantes recurrieron alegando que el juez no se había pronunciado sobre el discernimiento de la víctima, en su concepto, condición necesaria para aplicar la norma, la Corte Suprema sostuvo: "Que de conformidad a los principios que regulan la responsabilidad extracontractual, parece evidente que para aplicar la reducción a que se refiere el artículo 2330 del Código Civil, el sujeto que se expuso al peligro debe ser capaz de incurrir en culpa o imprudencia" (considerando $3^{\circ}$ ). Actos seguido agrega que "en el caso que nos ocupa, los sentenciadores, dentro de las facultades que le confiere la ley, en forma implícita, y atendidos los fundamentos contenidos en los considerandos $2^{\circ}$ y $3^{\circ}$ de su fallo, determinaron que el menor había actuado con discernimiento y como consecuencia de ello era procedente la reducción prevista en el ya citado artículo 2330" (considerando $\left.5^{\circ}\right)^{107}$.

(ii) A propósito del suicidio cometido por un paciente que se encontraba internado en el hospital de Dipreca y que fue víctima de un episodio de confusión temporo-espacial. El tribunal de primera instancia, en sentencia confirmada por la Corte de Apelaciones de Santiago, negó que el paciente hubiere ocurrido en "imprudencia", es decir, en culpa y, como consecuencia de ello, negó también la aplicación del artículo 2330. Al efecto sostuvo: “(...) En cuanto a la alegación del demandado en torno a que la muerte del Sr. Hauck se debió no a un procedimiento clínico, sino al hecho de haberse arrojado al vacío desde un tercer piso, y por ende debe aplicarse lo dispuesto en el artículo 2330 del Código Civil, cabe recordar que la víctima se encontraba atravesando por un episodio confusional agudo y temporal, y, por lo tanto, no se encontraba en pleno uso de sus facultades mentales que le permitieran razonar coherentemente las consecuencias de sus actos y decisiones, episodio al que él no se expuso

107 Valenzuela Luis con Narváez Filomena (1996). 
imprudentemente sino que fue la culminación de una serie de acontecimientos conexos, que ya se han descrito en lo precedente, tales como una hipersensibilidad al medicamento que se le administraba, una pérdida del sentido de realidad, exacerbado por las contingencias laborales que atravesaban los empleados del hospital, el fácil acceso a noticias etc., circunstancias todas que no permiten a esta Magistratura estimar que se expuso deliberada e imprudentemente a tal daño" (Considerando trigésimo séptimo) ${ }^{108}$.

(iii) A propósito del accidente sufrido por un niño de tres años, que sufrió daño producto de una escala mal cuidada por su madre, quien luego demanda de responsabilidad al recinto hospitalario que había dado de alta al niño. En este caso, el tribunal de instancia aplicó la reducción del daño moral demandado por la madre en representación del niño, aduciendo el artículo 2330. La demandante recurre de casación, alegando la infracción de esta norma. Sobre el punto, la Corte Suprema afirma: "tampoco es cierto que los sentenciadores hayan elevado a la calidad de causa natural la actuación deficiente de la madre del menor, puesto que ellos sólo le han atribuido la calidad de exposición imprudente al riesgo, procediendo a disminuir el monto de la indemnización conforme al artículo 2330 del Código Civil. Así, aun cuando esta Corte no comparte tal reducción, -puesto que no se puede sostener que un niño de 3 años se exponga imprudentemente al riesgo, ni tampoco que los actos realizados por un tercero (madre) impliquen una exposición de la víctima- ella deja de manifiesto un hecho concreto, esto es, que la actuación de la madre jamás ha sido considerada por los sentenciadores como causante del daño, pues sólo la han tomado en consideración para regular el quantum de la indemnización, cuestión que se relaciona directamente con la extensión de los perjuicios y no con la existencia de los mismos". (Decimocuarto) ${ }^{109}$. Si bien no se casa la sentencia, la Corte Suprema sostiene que un niño de tres años no puede incurrir en imprudencia, esto es, en culpa.

(iv) A propósito del accidente sufrido por un menor de tres años, quien cayó de un autobús en movimiento. Habiendo acogido el recurso de casación, en la sentencia de reemplazo, la Corte Suprema sostuvo que "Sin perjuicio de haberse establecido como causa determinante del accidente de que se trata, la conducta antirreglamentaria del demandado Bello, no es menos cierto que el descuido de los padres de la víctima es evidente, procediendo, por lo tanto, dar aplicación a la norma del artículo 2330 del Código Civil, disposición que recoge el principio de la igualdad entre las partes que regula las relaciones de derecho privado y que se traduce en que la culpa de la víctima contribuye a la

108 Hauck con Dirección de Previsión de Carabineros de Chile (2014).

109 Muñoz Saavedra Jessica y otros con I. Municipalidad de Putaendo y otro (2013). 
producción del daño o al aumento de su intensidad, aun cuando en el caso el afectado es incapaz, en la medida en que es en los progenitores en quienes la ley deposita el deber de cuidado necesario al respecto, quienes se encontraban presentes al momento de los hechos y a los que debe exigírseles la conducta razonable y prudente que las circunstancias justificaban, es decir, asegurar al menor con el que viajaban en un bus de transporte colectivo-aunque no en sus funciones habituales-." (Considerando Noveno). // Que, en dichas condiciones, este Tribunal estima del caso otorgar una suma única y total por concepto de indemnización por el daño moral sufrido por los padres y el menor afectado, ascendente a \$4.000.000.-, con los reajustes e intereses que se consignaran en lo dispositivo de este fallo. (Considerando décimo) ${ }^{110}$. Como se aprecia, la Corte entiende que no puede atribuirse "imprudencia" a un menor incapaz de cometer delito o cuasidelito, sin perjuicio de que, en última instancia, igualmente considera el artículo 2330 para regular tanto la indemnización de los padres como del niño.

\section{Conservación de la noción subjetiva de culpa en el ordenamiento chileno: alcance de esta afirmación}

En los párrafos anteriores, ha quedado demostrado que en su redacción el Código Civil chileno recogió el concepto clásico de culpa correspondiente a la tradición romano germánica en que se inserta ${ }^{111}$, la cual exige que el sujeto haya alcanzado suficiente discernimiento ${ }^{112}$. De esta manera, en la estructura de

\footnotetext{
110 Hernández Fuentes, Alex con Ruiz Nuñez, Arsenio (2012).

111 Sobre las incongruencias a que puede llevar la adopción de la noción de culpa objetiva en países regidos por el Código de Bello, Mantilla y Ternera (2005), pp. 213-230, especialmente pp. 222 ss.

112 Esto es así sin perjuicio de que se haya consagrado una suerte de presunción de derecho en orden a que a los dieciséis años de edad todas las personas tienen suficiente discernimiento. En este sentido, la situación es semejante a la que describe Cane cuando afirma que "al juzgar si la conducta de una persona fue razonable o no, la edad ha de ignorarse a menos que la persona fuera demasiado joven aún para haber desarrollado las habilidades mentales y sociales impartidas por la educación y la experiencia, y que resultan necesarias para tener una apreciación madura del riesgo. Esta regla se basa en una concepción unitaria de la adultez que, aunque tal vez científicamente cuestionable, parece ser sólida desde un punto de vista ético. Los adultos que no pueden tomar precauciones razonables no deberían emprender actividades riesgosas; pero si lo hacen, no pueden quejarse si se les exige asumir las consecuencias. (....) Éticamente, la regla podría parecer dura con los demandados; pero considerando a las dos partes, parece justo que el riesgo de la falta de experiencia o destreza recaiga sobre el agente del daño antes que en la víctima, especialmente ya que cualquier falta de esta última en cuidar razonablemente de sus propios intereses puede ser sancionada como "negligencia contributiva" o "aceptación voluntaria del riesgo (...). El principio ético que subyace a esta regla es que (...) las personas debieran reconocer sus propias limitaciones y ajustar sus actividades acordemente". CANE (2011), pp. 75-76; en Chile, una afirmación equivalente puede observarse en Domínguez (1989), p. 117.
} 
la responsabilidad concebida por Andrés Bello, la imputabilidad o capacidad es un elemento integrante de la culpa y no presupuesto de la responsabilidad civil en general, ni tampoco una causal de exención de responsabilidad, todo lo cual es consecuencia de la noción subjetiva de culpa. Así lo aceptó pacíficamente la doctrina tradicional antes citada. Como contrapartida, los incapaces de culpa son perfectamente responsables en las hipótesis de responsabilidad objetiva. Ahora bien, sin perjuicio de una cierta inclinación doctrinaria hacia la noción objetiva de culpa, lo cierto es que la estructura originaria no ha sido conscientemente puesta en tela de juicio, ni en doctrina ni en jurisprudencia. En efecto, la investigación realizada no encontró antecedentes de que se hubiera discutido expresamente el rol de la imputabilidad, ya sea para afirmar que los incapaces del artículo 2319 incurren en culpa o bien para analizar si responden o no en sede de responsabilidad objetiva. Por otro lado, según se dijo en el punto anterior, la escasa jurisprudencia que se ha pronunciado al respecto, lo ha hecho a propósito de la culpa de las víctimas incapaces, excluyendo la posibilidad de que estas puedan incurrir en exposición imprudente al daño, precisamente porque no pueden incurrir en culpa. En consecuencia, no cabe sino concluir que, hasta ahora, en Chile se ha conservado la noción subjetiva de culpa, que incluye la exigencia de discernimiento; por tanto, la imputabilidad constituye un requisito de la culpa, no un elemento independiente de la responsabilidad civil.

Sin perjuicio de que la discusión quede abierta, pues es necesaria una mayor reflexión en torno al punto, resulta oportuno poner de presente algunas ideas preliminares relacionadas con el significado de la conservación de la noción subjetiva de culpa. Al respecto, es necesario señalar que la existencia de una noción subjetiva de culpa no comporta la obligación de analizar los motivos sicológicos que impulsaron al sujeto a actuar, ni tampoco que deben apreciarse sus facultades o habilidades personales, sino solamente que el acto debe haber sido voluntario y consciente: con discernimiento y posibilidad real de abstención. Tampoco significa que deba analizarse la representación del daño por parte del sujeto, pues basta con la previsibilidad objetiva del daño $0^{113}$. En efecto, a diferencia de lo que ha ocurrido en otros países, en Chile nunca se ha

113 En este sentido la Corte Suprema ha expresamente resuelto que "La previsibilidad no hace referencia a un fenómeno psicológico, sino a aquello que debió ser previsto, atendidas las circunstancias. Como ocurre en general con los elementos del juicio de negligencia, la previsibilidad se valora en abstracto, considerando el discernimiento de una persona diligente. Así, se ha fallado que "no hay culpa cuando el hecho no pudo razonablemente ser previsto". En igual sentido se ha declarado que cuando se actúa con culpa "el agente infringe el deber exigible, menospreciando la atención y cuidado que debe en su obrar, a los bienes o intereses ajenos, pudiendo y debiendo prever el daño que en ellos causaría si ejecuta el acto voluntario". Danke de la Harpe, Enzo Osvaldo con Fisco de Chile y otros (2013). 
intentado introducir la idea de diligentia quam suis o culpa en concreto como parámetro para determinar la culpa del agente ${ }^{114}$, ni siquiera en materia contractual; ella siempre ha sido establecida en relación con un modelo abstracto, así se desprende claramente del artículo 44 CC. y de la doctrina antes citada ${ }^{115}$.

De esta manera, al margen de la falta involuntaria de razón o discernimiento, el hecho de que el sujeto en realidad carezca de las aptitudes físicas o intelectuales para llevar a cabo la actividad o para prever el resultado dañino de su actuar, en principio, no es obstáculo para considerarlo en culpa, pues, desde el Derecho romano incurre en culpa quien emprende una actividad, sabiendo o debiendo saber que carecía de las aptitudes para llevarla a cabo o que por falta de atención no previó sus consecuencias, así como quien se coloca a sí mismo en la posición de no poder controlar sus propios actos. En Chile, esta última idea se encuentra recogida en el artículo 2318 CC. cuando sanciona expresamente la responsabilidad del ebrio, disposición que la doctrina ha hecho extensiva a todas las privaciones voluntarias de razón. Como bien afirma Barros, a propósito de quien causa un accidente a raíz de una grave afección cardiaca que le impide reaccionar prontamente, "la responsabilidad se funda en este caso en que, si bien circunstancialmente no hay dominio del hecho, hay control de la causa del hecho"116. Relacionando lo dicho con las deficiencias intelectuales o emocionales, en principio, puede observarse un acercamiento entre la responsabilidad objetiva y la responsabilidad por culpa; sin embargo, aquí surge la dimensión de elemento distribuidor de riesgos propio de la cul$\mathrm{pa}^{117}$. En situaciones de normalidad, el riesgo de las propias debilidades queda

\footnotetext{
114 Para algunas consideraciones sobre la diligentia quam suis y sus raíces históricas, puede verse ZiMMERMANN (1996), pp. 210 ss.

115 En el mismo sentido Domínguez (2008), pp. 126 ss.

116 Cfr. Barros (2006), p. 88.

117 En este sentido, concordamos con Cane cuando afirma que "al juzgar si la conducta de una persona fue razonable o no, la edad ha de ignorarse a menos que la persona fuera demasiado joven aún para haber desarrollado las habilidades mentales y sociales impartidas por la educación y la experiencia, y que resultan necesarias para tener una apreciación madura del riesgo. Esta regla se basa en una concepción unitaria de la adultez que, aunque tal vez científicamente cuestionable, parece ser sólida desde un punto de vista ético. Los adultos que no pueden tomar precauciones razonables no deberían emprender actividades riesgosas; pero si lo hacen, no pueden quejarse si se les exige asumir las consecuencias. (....) Éticamente, la regla podría parecer dura con los demandados; pero considerando a las dos partes, parece justo que el riesgo de la falta de experiencia o destreza recaiga sobre el agente del daño antes que en la víctima, especialmente ya que cualquier falta de esta última en cuidar razonablemente de sus propios intereses puede ser sancionada como "negligencia contributiva" o "aceptación voluntaria del riesgo" CANE (2011), p. 75. Según el mismo autor, "el principio ético que subyace a esta regla es que (...) las personas debieran reconocer sus propias limitaciones y ajustar sus actividades acordemente". CANE (2011), p. 76.
} 
radicado en el sujeto que las padece, no en la sociedad, de manera que no deja de ser responsabilidad por culpa aquella en que la acción del sujeto concreto es comparada con la de un modelo ideal de conducta social ${ }^{118}$.

Finalmente, en relación con la previsibilidad del daño, por las mismas razones antes expuestas, el riesgo de la propia incapacidad para anticipar un resultado dañino, en circunstancias que un sujeto medio sí podría hacerlo, queda de cargo del agente y no de la víctima. Con todo, si bien esta afirmación resulta teóricamente impecable, sería necesario un ulterior análisis jurisprudencial para establecer exactamente cuál es la aplicación práctica que los jueces hacen de esta noción de previsibilidad, pues, a nuestro juicio, es altamente probable que ocurra algo similar a lo que, según sostiene Visintini, ocurre en la práctica de la jurisprudencia italiana a la hora de construir el estándar o modelo de comparación. Según esta autora, en aquellos casos en que la responsabilidad se funda exclusivamente en la culpa, es decir, cuando no confluyen otros criterios de imputación como el riesgo o la utilidad, los jueces italianos consideran las circunstancias personales del agente para determinar la previsibilidad del daño y, por esta vía, introducen criterios de culpa en concreto ${ }^{119}$. Desafortunadamente, atendido que un esfuerzo semejante escapa a la finalidad de este trabajo, tal análisis deberá quedar para una próxima oportunidad.

\section{Conclusiones}

En el Derecho comparado moderno, la noción de culpa admite dos nociones, una noción objetiva, de raíz francesa, en que se considera exclusivamente la disconformidad de la conducta del sujeto con la del modelo;

\footnotetext{
118 Esta idea se aprecia claramente en Coleman quien, defendiendo la noción objetiva de culpa, luego de haber expuesto su idea de que la responsabilidad por culpa es también (en algunos casos) responsabilidad objetiva, porque mira al acto no al sujeto, afirma "puede expresarse la diferencia entre la responsabilidad por culpa y la responsabilidad objetiva mediante la distinción entre culpa en la acción y culpa en el actor. La responsabilidad por culpa, en especial la negligencia, requiere culpa en la acción, pero no en el actor. La responsabilidad objetiva no requiere de ninguna de ellas". Coleman (2010), pp. 226-227. En Chile, algunas consideraciones sobre el rol de la culpa como factor de distribución de riesgos, si bien no desde esta misma perspectiva, han sido efectuadas en AEDO (2014), pp. 705-728.

119 La prestigiosa autora italiana, luego de haber señalado que en Italia rige el carácter objetivo de la previsibilidad del daño y el hombre medio como estándar de conducta, afirma que la recepción de la categoría del hombre medio es meramente formal, pues en la práctica los jueces analizan el requisito de la previsibilidad del daño teniendo en consideración las circunstancias, las posibilidades y la cultura del agente. Agrega que sólo se mantiene un estricto apego a la categoría del hombre medio cuando se trata de actividades en que la previsibilidad es en re ipsa a causa del elevado riesgo de daños que ellas conllevan, casos en los cuales en realidad la culpa no es el criterio de imputación de responsabilidad. VISINTINI (2014), pp. 61 ss.
} 
y una subjetiva, correspondiente a la formulada en la tradición romanogermánica. En esta, la culpa exige la presencia en el agente de cierto grado de raciocinio y ciertas condiciones mentales para que su comportamiento sea susceptible de un juicio de reproche jurídico. En particular, la culpa supone la capacidad para controlar los propios actos, cuestión que exige una cierta madurez mental, Ilamada discernimiento, que no se presenta de igual forma en todos los sujetos, sino que debe juzgarse caso a caso. En consecuencia, en esta segunda noción, la imputabilidad (o capacidad delictual) constituye un componente (o al menos un presupuesto) de la culpa y no tiene el carácter de elemento independiente de la responsabilidad civil. Como contrapartida, este requisito rige exclusivamente en la responsabilidad por culpa y no en la responsabilidad objetiva.

El análisis efectuado en este trabajo ha permitido concluir que, en la medida que los antecedentes históricos de nuestro Código Civil se fundan claramente en la noción subjetiva de culpa, cuando el artículo 2319 establece que hay ciertas personas incapaces para cometer delito o cuasidelito, entiende que ello se debe a que estas personas no pueden incurrir en culpa. Tradicionalmente, esta idea ha sido pacíficamente aceptada y afirmada por la doctrina, pero tales afirmaciones se han visto matizadas por algunas opiniones que dan a entender que la imputabilidad es un elemento independiente de la responsabilidad civil, desconectado de la culpa, exigible también en hipótesis de responsabilidad objetiva. Sin embargo, estas ideas no han sido profundizadas, de manera que no se han analizado sus consecuencias. Así, nadie ha sostenido abiertamente que los dementes o los menores de siete años incurren en culpa, ni tampoco que el artículo 2319 se aplica a hipótesis de responsabilidad objetiva. Por otro lado, en las escasa ocasiones que alude al argumento, la jurisprudencia da a entender que la imputabilidad está ligada a la culpa, toda vez que se niega que los inimputables puedan incurrir en imprudencia a efectos de aplicar el artículo 2330 CC. De esta manera, sin perjuicio de una creciente tendencia hacia la noción objetiva de culpa, es dable concluir que en Chile se ha conservado la estructura originaria de la responsabilidad civil, en que la imputabilidad es un componente de la culpa y no un elemento independiente.

Lo anterior no significa que esa estructura deba necesariamente perpetuarse, pues los ordenamientos jurídicos evolucionan, generando cambios en sus instituciones; sin embargo, también es cierto que la afirmación de estos cambios supone un razonamiento más o menos consciente, cuestión en este caso aún no se ha producido. Este trabajo habría cumplido cabalmente su objetivo si logra convocar a los estudiosos de la responsabilidad civil a reflexionar críticamente sobre el argumento, con el fin que al cabo de algunos años tengamos más claridad sobre el punto. 


\section{BibLIOGRAFÍA}

Abeliuk Manasevich, René (2014): Las obligaciones, $6^{\mathrm{a}}$ ed. (Santiago, Editorial Legal Publishing - Thomson Reuters), tomo I.

Aedo Barrena, Cristián (2006): Responsabilidad extracontractual, (Santiago, Editorial Librotecnia).

Aedo Barrena, Cristián (2010): Culpa aquiliana: una conjunción de aspectos históricos, filosóficos y dogmáticos, tesis doctoral, Bilbao, Universidad de Deusto, no publicada.

Aedo Barrena, Cristián (2013): "El tratamiento dogmático de la culpa de la víctima en la responsabilidad civil: un enfoque desde la imputación objetiva", en: A.A. V.V., Estudios de derecho civil VIII, (Santiago, Editorial LegalPublishing - Thomson Reuters, pp. 505-523.

Aedo Barrena, Cristián (2014 a)): "El concepto normativo de la culpa como Criterio de distribución de riesgos. Un análisis jurisprudencial", en: Revista Chilena de Derecho (Año 2014, № 2), pp. 705-728.

Aedo Barrena, Cristián (2014 b)): "El problema del concepto de la culpa en la lex Aquilia: una mirada funcional", en: Revista de Derecho (Valdivia) (Año 2014, No 1), pp. 27-57.

AlesSANDri Rodríguez, Arturo (2004): De la responsabilidad extracontractual en el derecho civil chileno, reimpresión con prólogo de René Abeliuk M., (Santiago, Editorial Jurídica de Chile).

Alpa, Guido (1990): "Danno ingiusto e ruolo della colpa. Un profilo storico", en: Rivista di diritto civile, (Año 1990, parte II).

BACACHe-Gibeilı, Mireille (2007): Les obligations. La responsabilité civile extracontractuelle, (Paris, Editorial Económica).

Bahamondes, Claudia y Pizarro, Carlos (2012): "La exposición de la víctima al daño: desde la culpabilidad a la causalidad", en: Revista de Derecho de la Pontificia Universidad Católica de Valparaíso, (Año 2012, № 39).

Barcia Lehman, Rodrigo (2010): Lecciones de derecho civil chileno. De las Fuentes de las Obligaciones, (Santiago, Editorial Jurídica de Chile), tomo II.

Barros Bourie, Enrique (2005): "La culpa en la responsabilidad civil", en: Ensayos Jurídicos, № 1, disponible en: http://derecho.uahurtado.cl/web2013/ wp-content/uploads/2013/06/culpa-responsabilidad-civil.pdf [Visitado: 27/07/2016].

Barros Bourie, Enrique (2006): Tratado de responsabilidad extracontractual (Santiago, Editorial Jurídica de Chile).

Barros Bourie, Enrique (2008): "La responsabilidad civil como derecho privado", en: Estudios Públicos, No 112, Disponible en: http://www.cepchile. 
cl/la-responsabilidad-civil-como-derecho-privado-notas-sugeridas-por-la/ cep/2016-03-04/094744.html [Visitado: 27/07/2016]

BiAnCA, Massimo, (2004): Diritto Civile 5. La responsabilità, reimpresión (Milán, Giuffrè).

Blanc-Jouvan, Xavier (1957): “La responsabilité de l'infans", en: Revue trimestriel de droit civil (enero-marzo, 1957).

Bonomo, Donatella María Enza (2012): Infermità di mente e responsabilità civile, (Milán, Giuffrè).

CAne, Peter (2011): Anatomía del derecho de daños (Traducc. Daniel Arturo Carvallo Montes, et al., Santiago, Flandes Indiano).

Cannata, Carlo Augusto (1971): "Genesi e vicende della colpa aquiliana", en: Labeo, 17.

Cannata, Carlo Augusto (1996): Sul problema della responsabilità nel diritto romano, (Catania, Torre Editrice).

CARDILLI, Riccardo (1995): L'obbligazione di 'praestare' e la responsabilità contrattuale in diritto romano, (Milán, Giuffrè).

CARDILLI, Riccardo (1996): "Il ruolo della 'dottrina' nella elaborazione del 'sistema': I'esempio della 'responsabilità contrattuale", en: Roma e America ( No 1, 1996).

CAstresAnA, Amelia (2001): Nuevas lecturas de la responsabilidad aquiliana (Salamanca, Ediciones Universidad de Salamanca).

Celis Rodríguez, Rubén, (2001): La responsabilidad extracontractual (Santiago, Editorial Universidad Central).

ChaBAS, François (2009): Cien años de responsabilidad civil en Francia (Traducc. Mauricio Tapia, Santiago, Flandes Indiano).

ChabAS, François (2011). "Responsabilidad civil del menor", en: A.A. V.V. Estudios de derecho civil (Santiago, Editorial Abeledo Perrot), pp. 469-473.

ChIRONI, Gian Pietro (2012): La colpa nel diritto civile odierno, Colpa extracontrattuale, Vol. 1 [reproducción anastática de la $2^{\text {a }}$ edición, Milano-TorinoRoma: Fratelli Bocca, 1903] (Nápoles, Edizioni Scientifiche Italiane).

Coleman, Jules (2010): Riesgos y daños (Traducc. Diego M. Papayannis, MadridBarcelona-Buenos Aires, Marcial Pons).

Contreras Moreno, Claudio (2009): La responsabilidad civil extracontractual: visión crítica y análisis jurisprudencial (Santiago, Editorial Parlamento).

CORRAL TALCIANI, Hernán (2013): Lecciones de responsabilidad extracontractual, $2^{\mathrm{a}}$ ed. (Santiago, Editorial LegalPublishing - Thomson Reuters).

CURSI, María Floriana (2002): Inuria cum damnum. Antigiuridicità e colpevolezza nella storia del danno aquiliano (Milán, Giuffrè). 
D'AGata, Antonella (2014): "L'imputabilita' (art. 2046 c.c.)", en: Diritto \& Diritti, Disponible en: http://www.diritto.it/docs/36152-I-imputabilita-art-2046-c-c [Visitado: 11/07/2016].

De CUpIS, Adriano (1975): El daño. Teoría general de la responsabilidad civil (Traducc. Ángel Martínez Sarrión, Barcelona, Editorial BOSCH).

Demogue, René (1923): Traité des obligations en général (Paris, Librairie Arthur Rousseau).

De Salas Murillo, Sofía (2003): Responsabilidad civil e incapacidad, (Valencia, Editorial Tirant lo Blanch).

Delvincourt, Claude Étienne (1813): Cours de Code Napoléon (Paris, Editorial P. Gueffier).

Díez Schwerter, José Luis (1997): El daño extracontractual (Santiago, Editorial Jurídica de Chile).

Díez-PICAzo, Luis (2011): Fundamentos de derecho civil patrimonial V (Madrid, Civitas - Thomson Reuters).

Domat, Jean (1697): Les loix civiles dans leur ordre natural (2a ed., Paris, P. Aubouin, P. Emery y C. Clouzier).

Domínguez Águila, Ramón (1966): "El hecho de la víctima como causal de exoneración de responsabilidad civil", en: Revista de derecho Universidad de Concepción, (Año 34, № 136).

Domínguez Águila, Ramón (1989): “Aspectos contemporáneos de la responsabilidad civil", en: Revista de Derecho Universidad de Concepción (Año $\left.57, N^{\circ} 185\right)$.

Domínguez ÁGuila, Ramón (2008): “La culpa en el derecho civil chileno. Aspectos generales", en: Anales de Derecho UC. Temas de responsabilidad civil ( $\left.\mathrm{N}^{\circ} 3\right)$. Escribar Mandiola, Héctor (1923): "Responsabilidad civil sin culpa", en: Revista de Derecho y Jurisprudencia, (1923, № 20).

European Tort Group (2005): Principles of European Tort Law. Text and Commentary, (Viena - Nueva York, Springer).

Fernández Cruz, Gastón (2005): “De la culpa ética a la responsabilidad subjetiva: ¿el mito de Sísifo? (panorámica del concepto y del rol de la culpa en el derecho continental y en el Código Civil peruano)", en: Revista Themis, (2005, No 50).

Figueroa Yáñez, Gonzalo (2011): Curso de Derecho Civil, Tomo I, Las fuentes de las obligaciones (Santiago, Editorial Jurídica).

Fromageot, Henri (1891): De la Faute comme source de la responsabilité en droit privé (París, Arthur, Rousseau). 
García Del Corral, Ildefonso (2004): Cuerpo del derecho civil romano, [reimpresión anastática de la edición de Barcelona: Jaime Molina, 1889] (Valladolid, Lex Nova).

Gomez Calle, Esther (1992): La responsabilidad civil de los padres, (Madrid, Editorial Montecorvo S.A.).

GuZMÁn BRITO, Alejandro (2013): Derecho privado romano, 2ª edición (Santiago, Editorial Thomson Reuters).

Honoré, Tony (1999): Responsability and Fault (Portland-Oxford, Hart Publishing). Josserand, Louis (1939): Cours de droit positiv français (3ª ed., París, Librairie du Recueil Sirey).

Larenz, Karl (1958): "Derecho de obligaciones" (Traducc. Jaime Santos Briz, Madrid, Editorial Revista de Derecho Privado).

Larroucau Torres, Jorge (2010): Culpa y dolo en la responsabilidad extracontractual: análisis jurisprudencial, (Santiago, Editorial Lexis Nexis).

Laurent, François (1876): Principes de droit civil français, (Tomo 20, París, A. Durand \& Pedone Lauriel),

LeÓN, Leysser (2005). "Incapacidad de discernimiento e "indemnización equitativa""', en: The Cardozo Electronic Law Bulletin Vol. 13, 2007. Disponible en: http://www.jus.unitn.it/cardozo/Review/2007/leon.pdf [Visitado: 19/07/2016].

LóPEZ MESA, Marcelo. "La culpa como factor de atribución de responsabilidad. (Cénit, ocaso y resurgimiento de la culpa)", en: Anuario da Facultades de Dereito da Universidade da Coruña, No 10, 2006, Disponible en: http://ruc.udc.es/dspace/bitstream/handle/2183/2458/AD-10-31. pdf? sequence=1 \&isAllowed=y [Visitado: 11/07/2016] .

López SÁnchez, Cristina (2001): La responsabilidad civil del menor (Madrid, Editorial Dykinson).

LuCASIEVICZ, George (1900), Des Conditions de la capacité civile étudiées au point de vue de l'état psychologique de I'agen (Paris, Librairie de la Société du Recueil Général des Lois et des Arrets et du Journal du Palais)

KozıoL, Helmut (2012): Basic Questions of Tort Law from a Germanic Perspective (traudcc. inglesa de Fiona Salter Townshend, Viena, Jan Sramek).

Magnus, Ulrich (2003): "La reforma del derecho alemán de daños", en: InDret 2/2003.

Maiorca, Carlo (1960): "Colpa civile (teoria gen.)", en: Enciclopedia del Diritto, tomo VII, (Milán, Editorial Giuffrè). 
Mantilla Espinosa, Fabricio y Ternera Barrios, Francisco (2005): "La noción de culpa en la responsabilidad extracontractual", en: Actualidad Jurídica, № 11.

MARCADÉ, Victor-Napoleón (1889): Explication théorique et pratique du code civil, $8^{a}$ ed. (Paris, Edittorial Delamotte Fils Et Cie).

MarkesinIs, Basil S. y Unberath, Hannes (2002): The German Law of Torts. A Compartive Treatise, $4^{\mathrm{a}}$ ed. (Oxford-Portland, Hart Publishing).

MARTIN-CASAls (2005): "Una primera aproximación a los Principios de Derecho europeo de la responsabilidad civil", en: InDret, 2/2005, disponible en: http://www.indret.com/pdf/284_es.pdf [Visitado: 02/05/2016].

Martín-CAsals, Miquel (2003): "A través del espejo: concurrencia de "culpa" de la víctima y culpa del causante del daño", en: A.A. V.V., Estudios jurídicos en homenaje al profesor Luis Díez-Picazo (Madrid, Editorial Thomson Civitas).

Martin-CAsals, Miquel (2005): “Líneas generales de los "Principios de Derecho europeo de la responsabilidad civil", en: Asociación Española de Abogados Especializados en Responsabilidad Civil y Seguros, Ponencias del $5^{\circ}$ Congreso Nacional. Pamplona, noviembre de 2005, (Granada, Grupo Editorial Universitario).

Martín-Casals, Miquel (editor) (2006): Children in Tort Law. Part II: Children as Tortfeasor (Viena-Nueva York, Springer).

Martín-Casals, Miquel (editor) (2007): Children in Tort Law. Part II: Children as Victims (Viena-Nueva York, Springer).

Martín-Casals, Miquel, Ribot, Jordi, Solé Feliu, Josep (2007): "Children as Victims Under Spanish Law", en: Miquel Martín-Casals (editor) Children in Tort Law. Part II: Children as Victims (Viena-Nueva York, Springer).

Mazeud, Henri, Mazeud, Léon y Tunc, André (1962): Tratado teórico y práctico de la responsabilidad civil, delictual y contractual (Traducc. Luis Alcalá Zamora y Castillo, Buenos Aires, Ediciones Jurídicas Europa-América).

Mazeaud, Henri, Maezaud, Léon, Mazeaud, Jean, Chabas, François (1991): Leçons de droit civil. Obligations théorie génerale (París, Montchrestien).

Medina Alcoz, María (2003). La culpa de la víctima en la producción del daño extracontractual. Madrid: Dykinson.

Meza Barros, Ramón (2010): Manual de Derecho Civil. De las fuentes de las obligaciones. Tomo II (Santiago, Editorial Jurídica de Chile 2010).

MicARI, Giuseppe (2005): "L'art. 1227 c.c. e l'incapacità naturale del danneggiato", en: Danno e responsabilità (№ 12/2005).

Momogliano, Walter (1937): "Il risarcimiento del danno extracontrattuale cagionato da persona priva di discernimento", en: Rivista di diritto civile, (1937, parte II). 
PothieR, Robert Joseph (2007): Tratado de las obligaciones (Traducc. Guillermo Cabanellas de Torres, Buenos Aires, Editorial Heliasta).

ProençA, José Carlos Brandão (2007): A conduta do lesado como pressuposto e criterio de imputação do daño extracontratual (Coimbra, Almedina).

Ramos Pazos, René (2006): De la responsabilidad extracontractual (Santiago, Editorial Thomson Reuters).

Reglero Campos, Fernando y Bustos Lago, José Manuel (2014): Tratado de responsabilidad civil, $5^{\text {a }}$ edición (Madrid, Aranzadi Thomson Reuters).

Rodríguez Grez, Pablo (2010): Responsabilidad extracontractual, 2ª ed., (Santiago, Editorial Jurídica de Chile).

Rosende Subiabre, Hugo (2000): "Algunos aspectos acerca de las nuevas tendencias sobre la responsabilidad civil extracontractual", en: Actualidad Jurídica ( No 2, 2000).

Rosso Elorriaga, Gian Franco (2002): "El buen padre de familia como criterio de apreciación de la culpa y su aplicación a la responsabilidad cuasidelictual", en A.A. V.V. Derecho de Daños (Santiago, Editorial LexisNexis).

Rotond, Giovanni (1922): "Dalla lex aquilia all'art. 1151 Cod. Civ. Ricerche storico dogmatiche", consultado en: Scritti giuridici, Vol. II (Milán, Ulrico Hoepli, previamente publicado en Rivista di diritto commerciale (XIV. 1916, I parte, pp. 942-970 y XV, 1917 I parte, pp. 236-295).

Ruz LÁrtiga, Gonzalo (2011): Explicaciones de Derecho Civil. Contratos y responsabilidad extracontractual (Santiago, Editorial Thomson Reuters).

Saleilles, Raymond (1897): Les accidents de travail et la responsabilité civile (Paris, Arthur Rousseau).

SAvigny, M.F.C. (2005): Sistema del derecho romano actual (vertido al castellano por Jacinto Mesía y Manuel Poley, edición especial íntegra, Barcelona, Comares).

SCHIEMman, Gottfried (2013): "§'823-830, 840, 842-853. Unerlaubte Handlungen (Deliktsrecht)", en Shmoekel, Mathias et alt Historisch-kritischer Kommentar zum BGB. Tomo III, (Tübingen, Mohr Siebeck).

SCHIPANI, Sandro (1969): Responsabilità 'ex Lege Aquilia'. Criteri di imputazione e problema della 'culpa' (Turín, Giappichelli).

SCHIPANI, Sandro (1995): El sistema romano de la responsabilidad extracontractual: el principio de la culpa y el método de la tipicidad, en: Atilio Aníbal Alterini y Roberto López Cabana, La responsabilidad, homenaje al profesor Isidoro Goldenberg, (Buenos Aires, Editorial Abeledo-Perrot).

SCHIPANI, Sandro (2009): Contributi romanistici al sistema della responsabilità extracontrattuale, (Turín, Giappichelli). 
SeubA, Joan C. et al. (2004): "Daños causados por personas con trastornos mentales", en InDret 2/2004.

SimaO, José Fernando (2008): Responsabilidades civil do incapaz (San Pablo, Atlas).

Talamanca, Mario (1960): "Colpa civile (storia)", en: Enciclopedia del Diritto, vol. VII (Milán, Giuffrè).

Tapia Rodríguez, Mauricio (2005): Código Civil 1855-2005 Evolución y Perspectivas (Santiago, Editorial Jurídica de Chile).

TAPIA SuARez, Orlando (2006): De la responsabilidad civil en general y de la responsabilidad delictual entre los contratantes, $2^{\text {a }}$ ed. (Santiago, Lexis Nexis).

Terry, Henry T. (1915): "Negligence" (Harvard Law Review, vol. 29, № 1).

Thomasius, Christian (2000): Larva Legis Aquiliae (Traducc. Margaret Hewett, Oxford, Editorial Hart Publishing).

VAlDitARA, Giuseppe (2005): Damnum iniuria datum, $2^{a}$ ed. (Turín, Giappichelli).

VINEY, Geneviève y JOURDAIN, Patrice (2006): Traité de droit civil. Les conditions de la responsabilité (París, L.G.D.J.).

VINEY, Geneviève (2007): Tratado de derecho civil. Introducción a la responsabilidad (Traducc. Fernando Montoy Mateus, Bogotá, Editorial Universidad Externado de Colombia).

VISINTINI, Giovanna (2014): Cos'è la responsabilità civile (Nápoles, Edizioni Scientifiche Italiane).

VON JHERING, Rudolph (2013): El elemento de la culpabilidad (Traducc. José Luis Guzmán Dalbora, Montevideo - Buenos Aires, Editorial IBdeF).

WAGNER, Gerhard (2007): "Children as Victim Under German Law", en: MartinsCasals, Miquel (editor), Children in Tort Law Part II: Children as Victims (Viena - Nueva York, Springer).

WinIger, Bénédict (2002): La responsabilité aquilienne en droit commun. Damnum Culpa Datum (Ginebra, Helbing \& Lichtenhahn).

YÁÑez Vivero, Fátima (2011): "La experiencia del Civil Law y del Common Law en el ámbito de la responsabilidad civil de las personas incapaces", en: Boletín mexicano de derecho comparado (nueva serie, año XLIV, núm. 132, septiembre-diciembre de 2011).

Zeno-Zencovich, Vincenzo (1986): "La colpa oggettiva del malato di mente: le esperienze nor-americane e francese", en: Responsabilità civile e previdenza, (vol. 51, 1986).

ZimmermanN, Reinhard (1996): The Law of Obligations (Oxford, Oxford University Press). 


\section{JURISPRUDENCIA CITADA}

Castilla Treviño, Guillermo con Sociedad Austral electricidad (2006): Corte Suprema 5 de marzo de 2007 (casación en el fondo), www.pjud.cl rol $N^{\circ} 603-2006$.

Danke de la Harpe, Enzo Osvaldo con Fisco de Chile y otros (2013): Corte Suprema, 12 de junio de 2013, en: www.pjud.cl rol № 2448-2010.

Hauck con Dirección de Previsión de Carabineros de Chile (2014): $4^{\circ}$ Juzgado Civil de Santiago, 16 de enero de 2014, rol № 8320-2012. Confirmada por Corte de Apelaciones de Santiago, 11 de septiembre de 2014, (apelación), en: www.pjud.cl rol 1651-2014.

Muñoz Saavedra, Jessica y otros con I. Municipalidad de Putaendo y otro (2013): Corte Suprema 10 de junio de 2013 (casación en el fondo), en: www.pjud. cl rol No 9554-2012.

Valenzuela, Luis con Narváez, Filomena (1996): Corte Suprema 9 de enero de 1996 (casación en el fondo), en: Microjuris, Identificador MJCH_MJJ115.

Hernández Fuentes, Alex con Ruiz Núñez, Arsenio (2012): Corte Suprema 25 de septiembre de 2012 (casación en el fondo), en: www.pjud.cl rol No 9942-2010. 
